\title{
Immunohistochemical distribution of PlexinA4 in the adult rat central nervous system
}

\section{Claire-Anne Gutekunst* , Eric N. Stewart and Robert E. Gross*}

Department of Neurosurgery, Emory University School of Medicine, Atlanta, GA, USA

\section{Edited by:}

Patrik Brundin, Lund University,

Sweden; Vetenskapsrådet, Sweden;

Nordic Center of Excellence, Norway;

NeuroFortis Strong Research

Environment, Sweden

\section{Reviewed by:}

Hwai-Jong Cheng, University of

California Davis, USA

Lahouari Amar, Lund University,

Sweden

\section{*Correspondence:}

Claire-Anne Gutekunst and Robert E.

Gross, Emory University School of

Medicine, Department of

Neurosurgery, Atlanta, GA 30322,

USA.

e-mail: cguteku@emory.edu;

rgross@emory.edu
PlexinA4 is the latest member to be identified of the PlexinA subfamily, critical transducers of class 3 semaphorin signaling as co-receptors to neuropilins 1 and 2. Despite functional information regarding the role of PlexinA4 in development and guidance of specific neuronal pathways, little is known about its distribution in the adult central nervous system (CNS). Here we report an in depth immunohistochemical analysis of PlexinA4 expression in the adult rat CNS. PlexinA4 staining was present in neurons and fibers throughout the brain and spinal cord, including neocortex, hippocampus, lateral hypothalamus, red nucleus, facial nucleus, and the mesencephalic trigeminal nucleus. PlexinA4 antibodies labeled fibers in the lateral septum, nucleus accumbens, several thalamic nuclei, substantia nigra pars reticulata, zona incerta, pontine reticular region, as well as in several cranial nerve nuclei. This constitutes the first detailed description of the topographic distribution of PlexinA4 in the adult CNS and will set the basis for future studies on the functional implications of PlexinA4 in adult brain physiology.

Keywords: semaphorin, axon guidance molecule, regeneration

\section{INTRODUCTION}

The semaphorins are a large family of axon guidance molecules comprising 19 secreted and membrane bound molecules organized into eight classes (Pasterkamp and Kolodkin, 2003). The best characterized of these are the class 3 semaphorins, which are secreted proteins with a diverse set of functions in developing animals including axon pruning and repulsion, dendritic attraction and branching, growth cone collapse, regulation of cell migration, and vascular remodeling (Potiron and Roche, 2005; Bussolino et al., 2006). Whereas class 3 semaphorins bind directly to either neuropilin 1 (Nrp1) or neuropilin 2 (Nrp2), signal transduction requires interaction with members of the A subfamily of Plexin co-receptors (PlexinA1-A4). PlexinA4, a type 1 membrane protein, transduces signals from semaphorin $3 \mathrm{~A}$ and $3 \mathrm{~F}$ (Sema3A and 3F) (Suto et al., 2003). Although its affinity for Nrp1 is greater than for Nrp2, PlexinA4 has been shown to interact with both depending on the location and presence of other co-receptors, such as PlexinA3 (Suto et al., 2003; Yaron et al., 2005). In the development of the sympathetic nervous system, PlexinA4 works cooperatively with PlexinA 3 to regulate the migration of sympathetic neurons and differentially to guide sympathetic axons (Waimey et al., 2008). PlexinA4 is also a direct receptor and transducer for the membrane-bound class 6 semaphorins, Sema6A and 6B (Suto et al., 2005; Okada et al., 2007).

In the mouse, PlexinA4 consists of 1890 amino acids including a likely signal sequence (amino acids, aa 1-20), a transmembrane domain (aa 1230-1255), and 12 extracellular, N-linked glycosylation sites. It also possesses certain domains that are characteristic of the other members of the PlexinA subfamily. Extracellularly, these include the Sema domain (aa 36-554), three MRS/cysteine clusters, and three glycine-proline repeats, and, intracellularly, the SP domains as well as a putative tyrosine kinase phosphorylation site (aa 1804-1811) (Suto et al., 2003).
Most PlexinA4 brain localization studies have focused on its mRNA distribution in the developing nervous system (Suto et al., 2003; Perala et al., 2005). In mouse embryos, PlexinA4 mRNA was found in both the central and peripheral nervous systems (CNS and PNS). High levels of mRNAs are present in the somatosensory, olfactory, auditory, and visual systems, the neocortex, and the hippocampal formation, as well as the choroid plexus (Perala et al., 2005). In addition, PlexinA4 mRNAs are found in the superior colliculus, the oculomotor nucleus, the dorsal motor nucleus of the vagus, the hypoglossal nucleus, several thalamic nuclei, the medial vestibular nucleus, and motor neurons (Suto et al., 2003; Spinelli et al., 2007). Lower levels are present in the spinal trigeminal nucleus of the oralis and the dorsal horn of the spinal cord (Suto et al., 2003). In the PNS, high levels of mRNAs are found in the dorsal root ganglia, trigeminal ganglia, vagus and glossopharyngeal ganglia, and the sympathetic and ciliac ganglia (Suto et al., 2003). PlexinA4 mRNA has also been found in mouse oligodendrocyte precursor cells (Okada et al., 2007). Outside of the nervous system, PlexinA4 mRNA has been found in the oral epithelium of the tongue, the pancreatic primordium, the enteric nervous plexus, the lamina propria, the muscularis externa of the intestine (Perala et al., 2005), and mouse T-cells, where its absence leads to an elevated immune response and increased T-cell proliferation (Yamamoto et al., 2008). Fewer studies have examined PlexinA4 protein distribution. It was detected in NG-2 expressing cells in primary cultures of mouse cerebral cortex (Okada et al., 2007). Expression of the protein was also found in the hippocampi of P1 and P10 mice, where it was seen mainly in mossy fibers, particularly the surprapyramidal and infrapyramidal bundles, as well as the dentate hilus (Suto et al., 2007). 
Due to the important role of plexins in the transduction of axon guidance signals in the developing nervous system, past studies have mainly focused on PlexinA4 mRNA distribution during different embryonic stages of development, with comparatively little attention being devoted to the study of its distribution and possible function in the adult brain. PlexinA4 mRNAs were shown to be expressed in both the facial nucleus and red nucleus in the adult, and axotomy increased PlexinA4 mRNA expression levels in both rubrospinal and facial motor neurons suggesting a role of PlexinA4 in regenerative processes (Spinelli et al., 2007). A fuller knowledge of the anatomical distribution of PlexinA4 should provide important context to further stimulate investigation of its physiological role in the adult brain. In the present study we describe the expression pattern of PlexinA4 protein throughout the adult rat CNS.

\section{MATERIALS AND METHODS ANIMALS AND PERFUSION}

Adult (2 month old) Sprague-Dawley rats (150-200 g) were obtained from Jackson Laboratories (West Chester, PA, USA) and maintained in a 12/12 light/dark cycle with ad libitum access to food and water. All protocols involving animals were approved by the Emory University Institutional Animal Care and Use Committee (IACUC) and conform to NIH guidelines.

\section{ANTIBODIES}

Rabbit polyclonal antibodies specific for PlexinA4 were used at 1:500 (ab39350-200, Abcam, Cambridge, MA, USA). Mouse monoclonal antibodies specific for NeuN were used at 1:100 (MAB377, Chemicon/Millipore, Billerica, MA, USA). Mouse anti-glial fibrillary acidic protein (GFAP) antibodies were used at 1:500 (AB5804, Chemicon/Millipore, Billerica, MA, USA).

\section{WESTERN BLOT}

Whole brain tissue from rat and mouse were homogenized in lysis buffer (0.25 M sucrose; $100 \mathrm{mM}$ Tris- $\mathrm{HCl})$ supplemented with protease inhibitor cocktail (Roche 11897100) followed by centrifugation at $600 \mathrm{~g}$ and $4^{\circ} \mathrm{C}$ for $10 \mathrm{~min}$. Supernatants were collected and protein content determined by BCA Protein Assay Kit (Thermo Scientific, Rockford, IL, USA) using a FL600 Microplate Fluorescence Reader (Bio-Tek, Winooski, VT, USA). Samples and Kaleidoscope ladder (Bio-Rad, Hercules, CA, USA) were separated on a $7.5 \%$ SDS-PAGE ReadyGel (Bio-Rad, Hercules, CA, USA). Gels were electroblotted onto supported nitrocellulose membrane (Millipore, Billerica, MA, USA). Membranes were then blocked in $5 \%$ non-fat dried milk in TBST (50 mM Tris buffered saline, $0.1 \%$ Tween 20) for $1 \mathrm{~h}$ before being incubated overnight with PlexinA4 antibodies $(3 \mu \mathrm{g} / \mathrm{ml})$. The membranes were then rinsed and transferred into TBST with DyLight 800 goat anti-rabbit secondary antibody (1:2000; Thermo Scientific, Rockford, IL, USA) for 1 h. Blots were imaged using the Odyssey Infrared Imaging System (LI-COR, Lincoln, NE, USA). Controls included preabsorption of antibodies with excess PlexinA4 peptide (ab39349; Abcam, Cambridge, MA, USA) for $1 \mathrm{~h}$ at room temperature (RT) prior to use.

\section{IMMUNOHISTOCHEMISTRY}

Adult male Sprague Dawley rats $(n=6)$ were used for light microscopic immunohistochemistry. Each rat was deeply anesthetized with an overdose of Euthasol ( $5 \mathrm{ml} / \mathrm{kg})$, injected intraperitoneally, and then perfused intracardially with $0.9 \%$ saline, followed by $4 \%$ paraformaldehyde in $0.1 \mathrm{M}$ phosphate buffer at $\mathrm{pH} 7.2(\mathrm{~PB})$ for $15 \mathrm{~min}$ at a rate of $20 \mathrm{ml} / \mathrm{min}$. Brains were removed and cryoprotected in $30 \%$ sucrose at $4^{\circ} \mathrm{C}$, sectioned in coronal, parasagittal, and horizontal planes at $50 \mu \mathrm{m}$ using a freezing microtome, collected in $\mathrm{PB}$, and rinsed in $0.1 \mathrm{M}$ phosphate-buffered saline (PBS), pH 7.2. Free-floating sections were incubated in $3 \%$ hydrogen peroxide to eliminate endogenous peroxidase and $0.1 \%$ TritonX-100, rinsed and preblocked in $4 \%$ normal goat serum (NGS) in PBS for $30 \mathrm{~min}$ at RT. Sections were incubated in primary antibodies in PBS containing $2 \% \mathrm{NGS}$ at $4^{\circ} \mathrm{C}$ for $48 \mathrm{~h}$, then rinsed and incubated for $1 \mathrm{~h}$ at $\mathrm{RT}$ in biotinylated antirabbit antibody (ABC Elite; Vector Laboratories, Burlingame, CA, USA) in PBS containing 2\% NGS. After several rinses in PBS, the sections were incubated in avidin-biotin complex (ABC Elite; Vector) for $90 \mathrm{~min}$ at $4^{\circ} \mathrm{C}$ and rinsed. Immunoreactivity was visualized by incubation in $0.05 \% 3,3^{\prime}$-diaminobenzidine tetrahydrochloride (DAB; Sigma, St Louis, MO, USA) and 0.01\% hydrogen peroxide in PBS, until a dark brown reaction product was evident (5-10 min). Controls included the omission of primary antibody and preabsorption of antibodies with excess PlexinA4 peptide (ab39349; Abcam, Cambridge, MA, USA) for $1 \mathrm{~h}$ at RT prior to use.

\section{DOUBLE-LABELED IMMUNOFLUORESCENCE}

Immunofluorescence was used to co-localize PlexinA4, NeuN and GFAP in rat brain. Free-floating sections were blocked in $4 \%$ normal donkey serum (NDS) and $0.1 \%$ Triton-X for $30 \mathrm{~min}$ at RT, rinsed, and incubated overnight at $4^{\circ} \mathrm{C}$ in rabbit anti-PleinxA4 (1:500) and mouse anti-NeuN (1:100) or mouse anti-GFAP (1:500) in PBS containing 2\% NDS. Sections were rinsed and incubated in Alexa 594 conjugated donkey anti-rabbit (1:1000; Jackson Immunoresearch, West Grove, PA, USA) and Alexa 488 conjugated donkey anti-mouse (1:1000; Jackson Immunoresearch, West Grove, PA, USA) in 2\% NDS for $1 \mathrm{~h}$ at RT. After rinsing, sections were mounted on glass slides with Fluoromount-G mounting medium (SouthernBiotech, Birmingham, AL, USA) for fluorescence. For each double-label experiment, controls included omission of one or both primary antibodies.

\section{ANALYSIS}

Sections were visualized using either a Leica DMIRE/2 automated inverted research microscope equipped with four fluorescent cubes and a monochrome and color digital camera or a confocal Zeiss 510 with META system equipped with Argon and HENE/3PMT lasers and a Ti-sapphire laser for two-photon excitation. The level of immunoreactivity in areas of interest was evaluated using a qualitative scale of + (weak), ++ (moderate), and +++ (strong). Numbers of somata and fibers were also approximated with a qualitative scale of 1 (low), 2 (intermediate), and 3 (high). The anatomical terminology used was based on the rat brain atlas of Paxinos and Watson (1998).

\section{RESULTS SPECIFICITY OF ANTIBODIES}

PlexinA4 was detected using a rabbit polyclonal antibody which was raised against a synthetic peptide conjugated to $\mathrm{KLH}$ and derived from within residues 500-600 of mouse PlexinA4 (Treefam gene 
ID:HENSMUSG00000029765H). This region is identical to that of rat PlexinA4 (Treefam gene ID:HENSRNOG00000013072H) suggesting that the anti-mouse PlexinA4 antibodies should detect rat PlexinA4. It is unlikely that the antibody cross reacts with other PlexinA or even other plexins since a BLAST search with the peptide used to produce the antibody does not show homology to rat PlexinA 2 or 3 , and only $62 \%$ identity with rat PlexinA1. On immunoblots of rat and mouse brain tissue, a protein band with an approximate molecular mass of $210 \mathrm{kDa}$ was detected (Figure 1A). This molecular mass is consistent with that predicted from the mouse and rat PlexinA4 sequences. Immunoreactivity was abolished when the antibodies were first preabsorbed with the PlexinA4 peptide (Figure 1B).

\section{GENERAL BRAIN DISTRIBUTION AND NEURONAL EXPRESSION}

PlexinA4-immunoreactive neurons were found in every region of the brain examined. In all cases, immunoreactivity was abolished when $1^{\circ}$ antibodies were preabsorbed against corresponding PlexinA4 peptide (Figure 1B) or were omitted (Figure 1C insert). Although PlexinA4 immunoreactivity was widespread in the rat brain, regional differences could be observed, with the most intense labeling being evident in the cortex, thalamus, colliculi, cerebellum and many nuclei of the brainstem, medulla and pons (Figure 1C). Individual laminae were intensely stained in some areas, such as layer $V$ of the cerebral cortex, the hippocampal pyramidal cell layer, and the Purkinje cell layer of the cerebellum (Figure 1C). In all regions examined, all PlexinA4 immunoreactive cells were also NeuN positive (Figure 1D), with no overlap between PlexinA4 and GFAP staining (Figure 1E). Within neurons, PlexinA4 immunostaining was cytoplasmic and had a punctate appearance with no PlexinA4 labeling detected in neuronal nuclei. This subcellular localization is consistent with PlexinA4 being a membrane localized receptor protein. The results are summarized in Table 1. In the following sections, the distribution of PlexinA4 immunoreactivity throughout the major areas of the adult rat brain will be described.

\section{CEREBRAL CORTEX}

The intensity of PlexinA4 staining was high in most of the regions of the cerebral cortex, especially the motor, primary auditory, primary visual, and somatosensory cortices. On coronal sections, there was no visible immunostaining in the insular and piriform cortices - the only cortical regions in which staining was not observed. Cortical staining began dorsal to the rhinal fissure at the level of the somatosensory cortex. The staining was particularly intense in the large and medium-sized pyramidal cells of layers II-III and V and apical dendrites of layers II-VI (Figures 2A-E). In addition, PlexinA4 labeling was present in large and medium-sized interneurons (Figure 2C). Within the pyramidal neurons, PlexinA4 immunostaining was visible in the perikarya around the nucleus as well as in the apical dendrites and axons (Figure 2D). In layer VI, PlexinA4 immunostained fibers heading for the corpus callosum were observed, where they were joined by other PlexinA4 positive fibers (Figure 2E). In the cingulate cortex, the PlexinA4 apical dendrites of the pyramidal neurons appeared to join together to form columns visible in both the horizontal and coronal planes (Figure 2F). In the sagittal plane these PlexinA4-positive dendritic columns could be seen amid unstained fields (Figures 2G,H). In a subregion of piriform cortex dorsally adjacent to the lateral olfactory tract (lot), PlexinA4 antibodies stained large pyramidal neurons and their dendrites (Figures 3A,B). The remainder of the pyramidal layer of piriform cortex was only very lightly stained.

\section{OLFACTORY SYSTEM}

PlexinA4 immunostaining was present in most layers of the main olfactory bulb (MOB). Labeled neurons were observed in the external plexiform (EPL) and mitral cell layer (MCL; Figures 3A,D,E). The mitral cells are the principal projection neurons in the olfactory bulb, receiving inputs from olfactory sensory neurons and in turn projecting via the lot to the olfactory cortex. PlexinA4 immunoreactivity was observed in the soma of the mitral cells as well as in their dendrites coursing through the EPL all the way to the necklace glomeruli (asterisks in Figure 3E). Based on their morphology, size, and position, PlexinA4 positive neurons in the EPL are likely to include external and middle tufted neurons as well as Van Gehuchten neurons (Figure 3E). In the internal plexiform layer (IPL), PlexinA4 stained axons of the tufted or mitral neurons projecting to the piriform cortex were observed. There was no detectable PlexinA4 in the anterior olfactory nucleus (AO; Figure 3D), but strongly stained axons in the lot could be seen (Figures $3 \mathrm{~A}-\mathrm{C}$ ). In the accessory olfactory bulb, PlexinA4 immunoreactivity was very light with only a few intensely stained fibers observed in the most posterior part of the bulb.

PlexinA4 immunoreactivity was present in the Islands of Calleja (ICj) where intense neuropil staining was seen in all of the ventral islands embedded in the olfactory tubercle and in the major island (ICjM) located between the septum, the diagonal band, and the nucleus accumbens (Figures 3F,H). Neuropil staining within the islands is consistent with terminal fields of efferent connections from piriform cortex, septum, nucleus accumbens, and amygdala (Fallon et al., 1978). Medial and dorsal to the ventral islands, PlexinA4-labeled fibers and neurons were seen in the ventral pallidum, diagonal band, lateral preoptic nucleus, and the magnocellular preoptic nucleus. Fibers in the ventral pallidal region include axons and dendrites of resident neurons as well as axons of the medial forebrain bundle originating in the ventral tegmental area (VTA) and the substantia nigra (see below). A few PlexinA4-positive fibers were also present in the lateral portion of the shell of the nucleus accumbens (data not shown).

\section{SEPTUM}

PlexinA4 immunoreactivity was seen throughout the septum where moderate staining of neurons and processes was observed in the dorsal division of the intermediate lateral septum (Figures 4A,D), the medial septal nucleus (Figure 4A) and the vertical limb of the diagonal band (VDB; Figures 4A,E). Intense PlexinA4 immunoreactive fibers were present in the septofimbrial nucleus (SFi; Figure $4 \mathrm{~B}$ ) and in the ventral hippocampal commissure (vhc) immediately caudal to the septum (Figure 4C).

\section{HIPPOCAMPAL FORMATION}

In the hippocampus, moderate PlexinA4 immunoreactivity was present in the CA1-CA4 pyramidal cell bodies (Figures 4F-J) with the most intense immunoreactivity seen in CA3 (Figure 4I). The granule cell layer neurons of the dentate gyrus (DG) also expressed moderate levels of PlexinA4 (Figure 4J). PlexinA4 labeling was also found in interneurons in the stratum oriens, pyramidal cell layer, and stratum radiatum. PlexinA4-positive interneurons located in the stratum oriens are likely to be either oriens lacunosum 
A

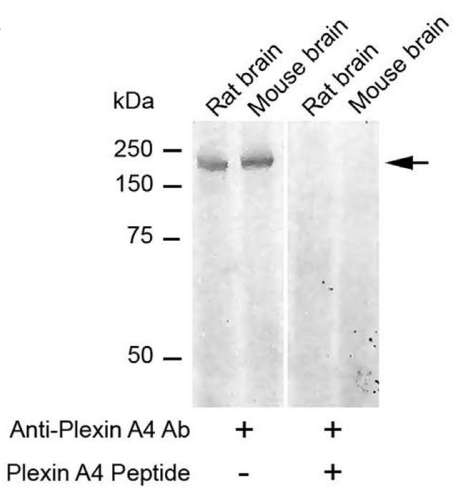

B

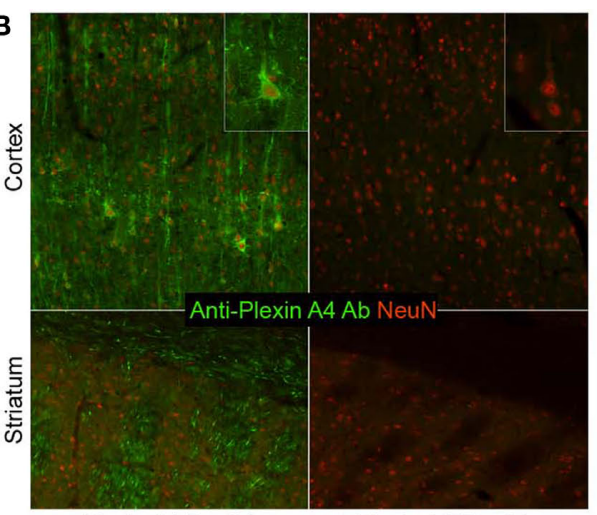

- Plexin A4 Peptide

+ Plexin A4 Peptide
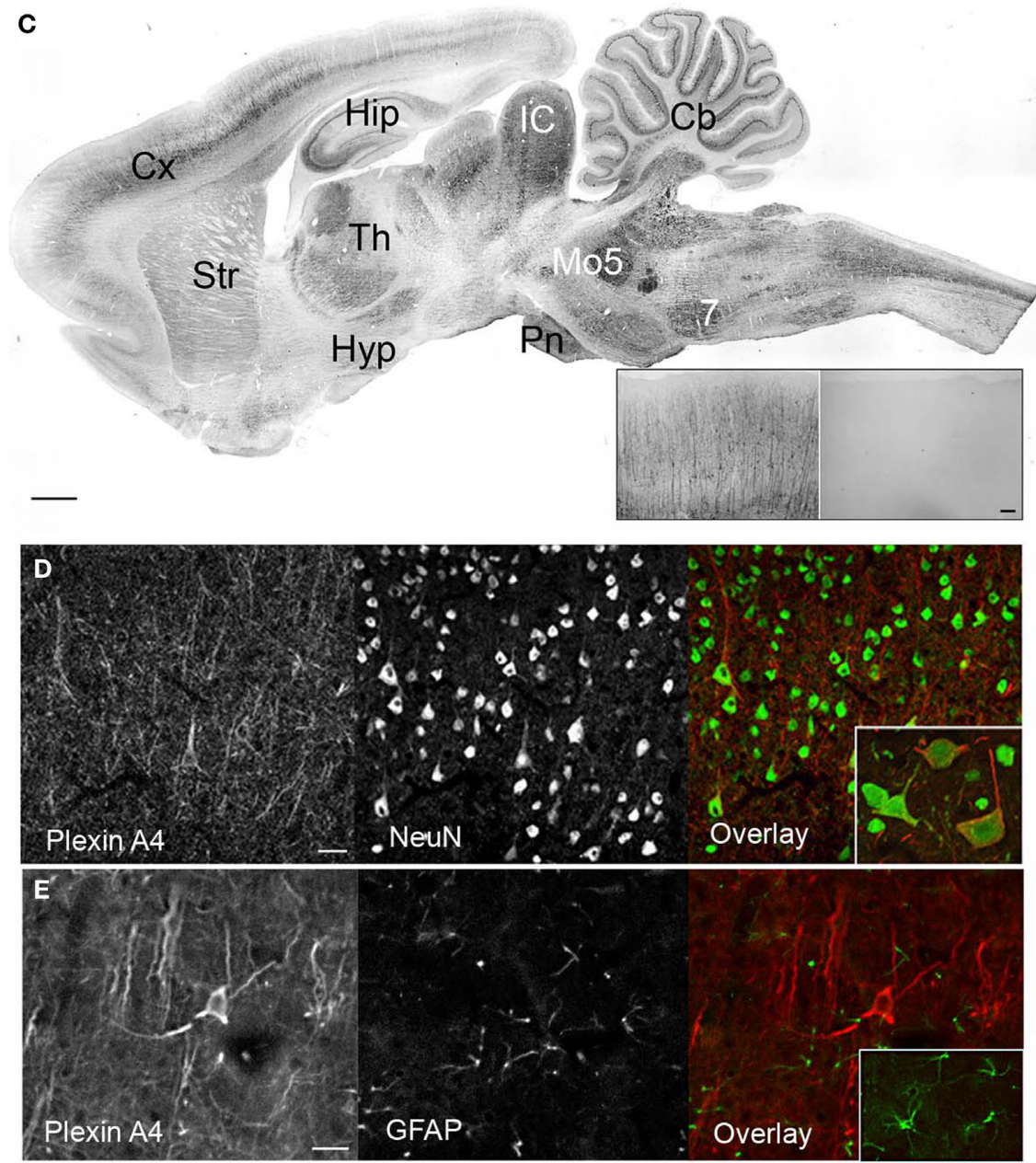

FIGURE 1 | Specificity of the polyclonal PlexinA4 antibodies. (A) Aliquots of rat and mouse brain tissue were subjected to SDS/7.5\% PAGE and immunoblotted with polyclonal anti-PlexinA4 antibodies. Molecular mass standards (in kDa) are indicated on the left. A band of $\sim 210 \mathrm{kDa}$ is detected in both rat and mouse tissue (arrow). (B) Representative coronal sections from PlexinA4 (green) and NeuN (red) co-immunostained rat cortex and striatum. PlexinA4 immunolabeling is abolished after preabsorption over excess PlexinA4 peptide. (C) Parasagittal section from an adult rat brain immunolabeled with PlexinA4 antibodies. PlexinA4 immunostaining is visible in many brain regions including $\mathrm{Cx}$, $\mathrm{Hip}, \mathrm{Str}, \mathrm{Cb}$, and brain stem nuclei. Insert shows coronal sections of $\mathrm{Cx}$ from an adult rat brain immunolabeled with either PlexinA4 (left) or no primary antibodies (right). No staining is visible in the no $1^{\circ}$ control tissue. (D) Coronal sections through cortex co-immunolabeled with PlexinA4 (red) and NeuN (green) as indicated. Insert shows higher magnification of neurons double labeled with PlexinA4 and NeuN. All PlexinA4 positive cells are also NeuN positive suggesting that PlexinA4 is expressed by neurons. (E) Coronal sections through cortex co-immunolabeled with PlexinA4 (red) and GFAP (green) as indicated. Insert shows higher magnification of GFAP positive glial cells. There is no overlap between PlexinA4 and GFAP staining suggesting that PlexinA4 is not expressed by glia. 7, facial nucleus; Cb, cerebellum, Cx, cortex; Hip, hippocampus; Hyp, hypothalamus; IC, inferior colliculi; Mo5, motor trigeminal nuclei; Pn, pontine nuclei; Str, striatum; Th, thalamus. Scale bars: (A) $1 \mathrm{~mm}$, (A) insert: $50 \mu \mathrm{m}$, $100 \mu \mathrm{m}$. 
Table 1 | Distribution of PlexinA4 in the adult rat brain.

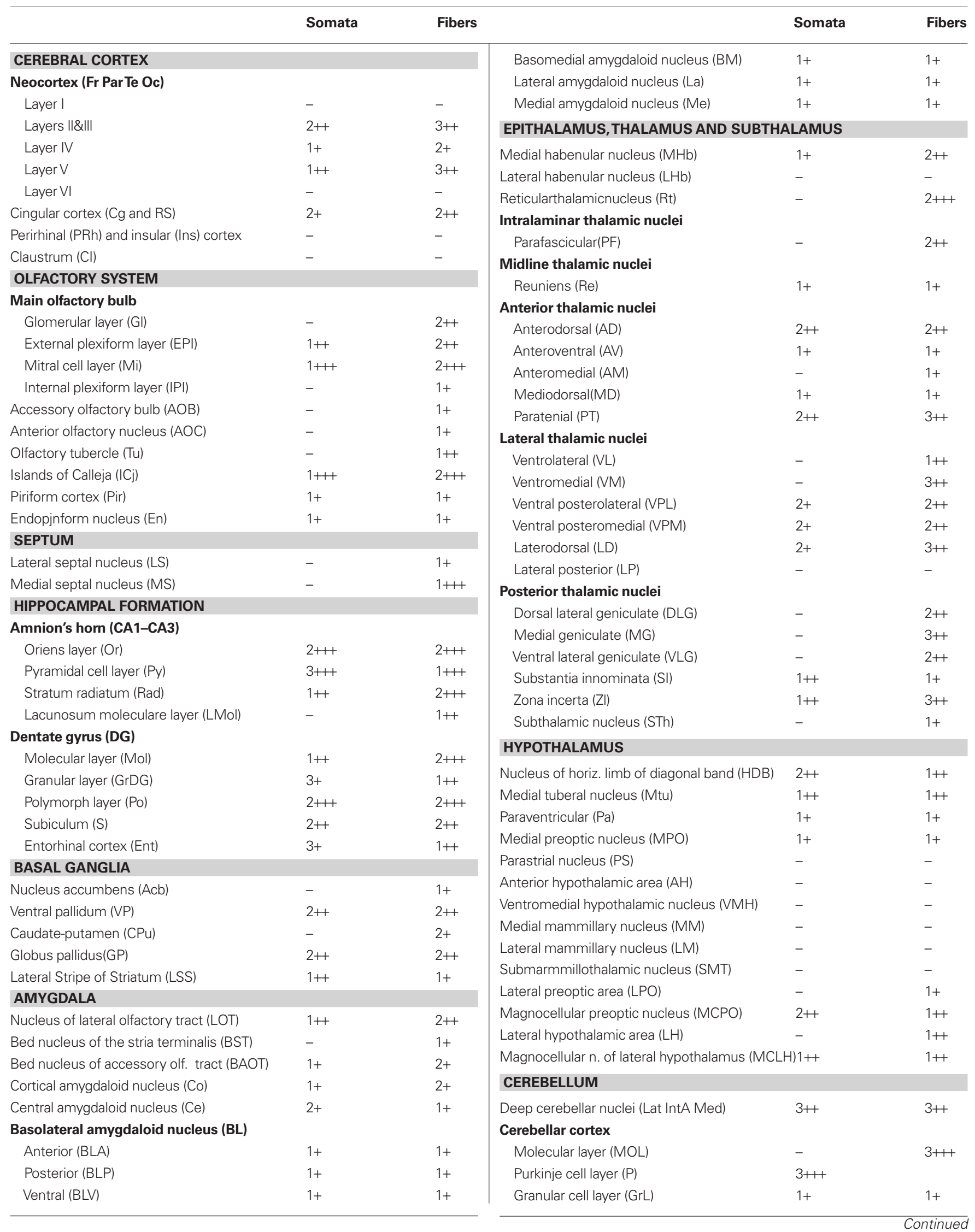




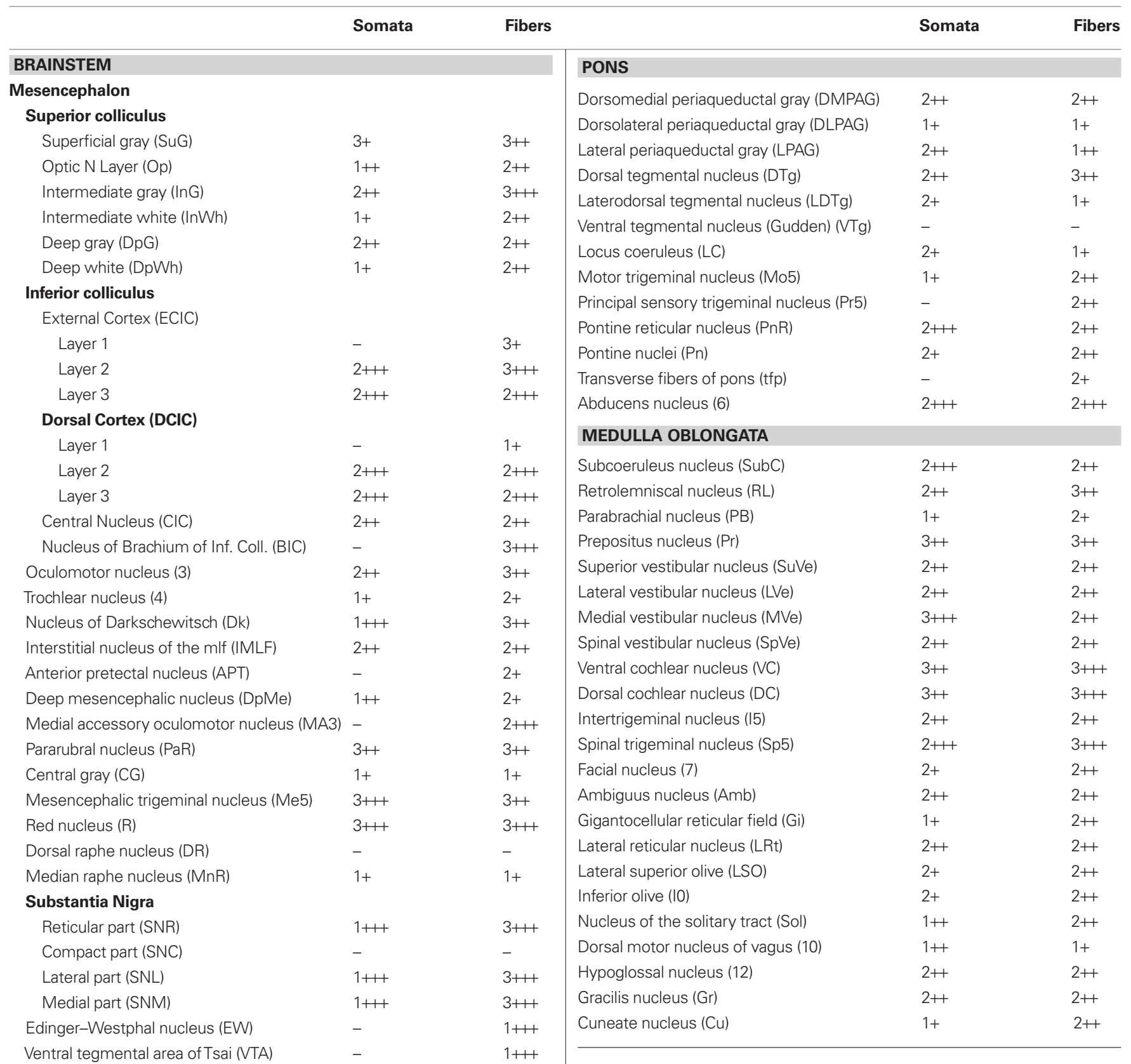

Intensity of staining: + , weak; ++ , moderate; +++ , strong. No. of somata

\section{INTERPEDUNCULAR NUCLEUS (IP)}

\section{Central nuclei (IPC 1 IPR)}

Lateral nuclei (IPL)

$1+\quad 2++$

$1+$

fibers: 1, low; 2, intermediate; 3, high.

molecular cells or horizontal trilaminar cells based on their cell body placement, oval-shaped somata and horizontally running dendrites (arrows in Figure 4G; Oliva et al., 2000).

\section{STRIATUM AND PALLIDUM}

In the striatum, PlexinA4 immunostaining was detected in the neuropil and in very few scattered neurons in the ventrolateral region (Figure 5). Their distribution, morphology, and number suggest that these large PlexinA4 immunostained neurons are a subgroup of aspiny cholinergic interneurons (Figure 5D). In the dorsal (dstr) and medial part of the striatum, immunoreactivity was most prominent in the neuropil (Figures $\mathbf{5 A}, \mathbf{B}$ ) whereas in the lateral striatum (lstr) staining of the neuropil was less visible (Figure 5C). Regional heterogeneity consistent with striosome or patch and matrix organization was not evident with PlexinA4 immunohistochemistry. Labeling was also present in myelinated 

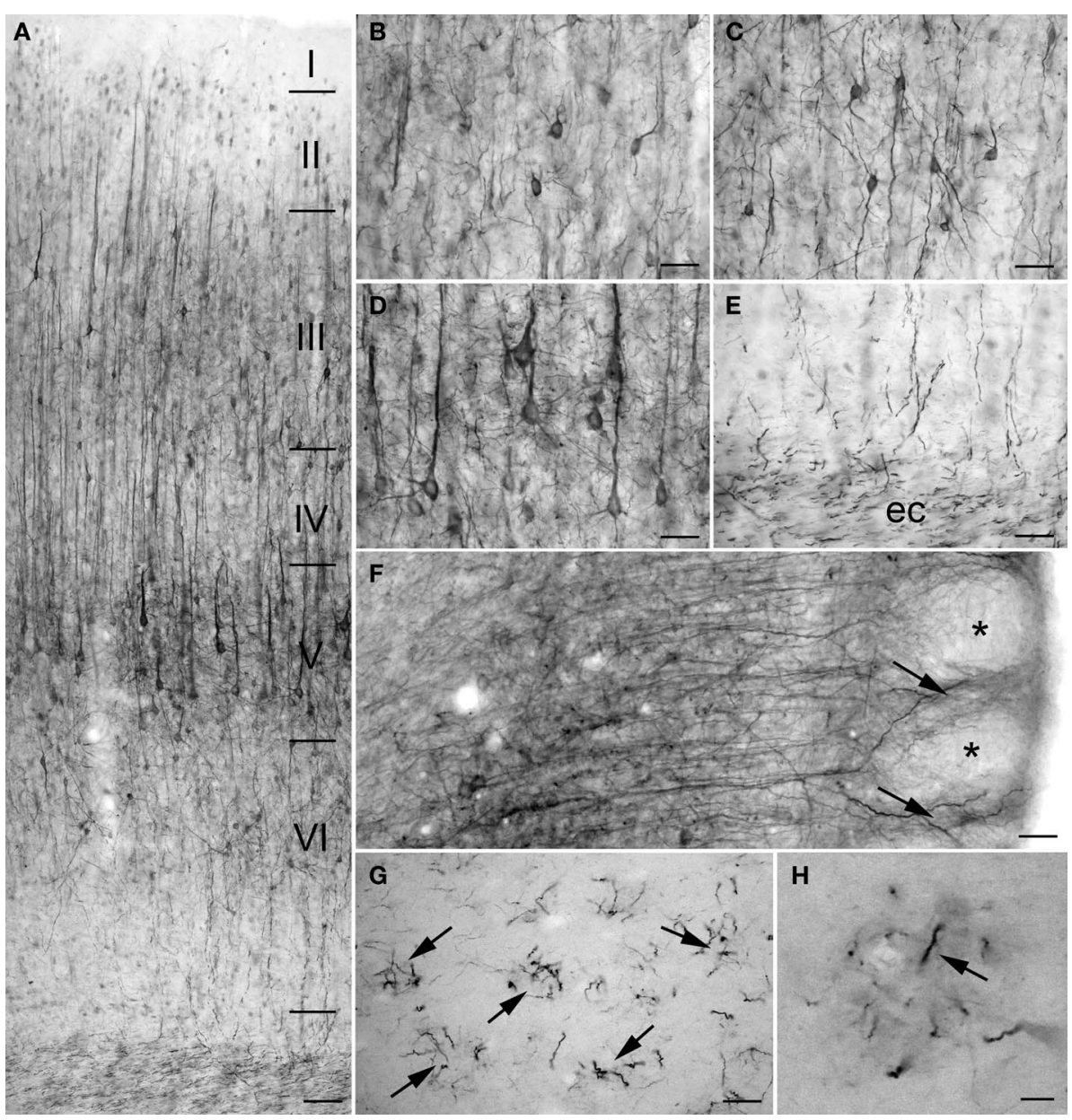

FIGURE 2 | PlexinA4 in cortex. Micrographs showing PlexinA4 immunostaining of motor (A-E) and cingulate (F-H) cortex. In coronal sections of cortex staining was most intense in the large and medium-sized neurons and their dendrites in layers II, III (B), V (D), and VI (C). Staining in axons coursing through the externa capsule (ec; E) suggests that PlexinA4 is present in cortico-striatal or corticofugal projections. (F) Micrograph of a coronal section through the cingulate cortex immunostained with PlexinA4. Apical dendrites from the pyramidal neurons are seen to form bundles in the upper layers of cortex (arrows) leaving unstained spaces $\left(^{*}\right)$ between them. A similar arrangement is visible in sagittal sections of cingulate cortex ( $\mathbf{G}$ and $\mathbf{H}$ ) where distinct bundles (arrows) of PlexinA4 positive fibers can be identified. ec, External capsule. (A) $200 \mu \mathrm{m}$, (B-G) $100 \mu \mathrm{m}$, (H) $25 \mu \mathrm{m}$. axons bundles traversing the striatum and in the internal capsule (Figures 5C,E). This finding together with PlexinA4 positive axons in the corpus callosum suggests that PlexinA4 is present in cortico-striatal projections. In the lateral globus pallidus (GP) PlexinA4 immunoreactivity was seen in neurons and their dendrites (Figure 5E). Occasional fibers extending into the adjacent striatum were also PlexinA4 positive.

\section{HYPOTHALAMUS AND AMYGDALA}

The level of PlexinA4 expression in the different hypothalamic nuclei varied from undetectable to moderate. In the anterior hypothalamus, PlexinA4 immunoreactive neurons were observed in a region including the magnocellular preoptic nucleus (MCPO; Figures 6A,D), and the more medial nucleus of the horizontal limb of the diagonal band (HDB; Figure 6A). A few neurons and their processes were also PlexinA4 positive in the lateral preoptic area (LPO; Figures 6A-C). Very little PlexinA4 immunoreactivity was seen in the remaining hypothalamic region with only scattered labeled neurons and proc- esses, except for a few strongly labeled neurons located at the dorsolateral edge of the optic tract (Figure 6G), and in a nucleus ventral to the magnocellular nucleus of the lateral hypothalamus (MCLH; Figures 6I-J). PlexinA4-positive processes were also visible in the optic chiasm (Figures 6A,H) dorsal to the optic tract (opt) around the ventrolateral hypothalamic tract (vlh; Figure 6K). Except for a few labeled neurons and processes in the anterior amygdaloid area (Figures 6E,F) there was no detectable PlexinA4 expression in the amygdala and the bed nucleus of the stria terminalis, an extension of the amygdala (Fudge and Haber, 2001).

\section{THALAMUS AND SUBTHALAMUS}

PlexinA4 immunoreactivity was more obvious in the thalamus compared to the hypothalamus. In the lateral thalamic nuclei, moderate PlexinA4 immunoreactivity was present in cell bodies of both the ventral posterolateral and ventral posteromedial nuclei (Figures 7A-D,F). Lightly stained PlexinA4 immunoreactive cell bodies were observed more dorsally in the mediocaudal part of 


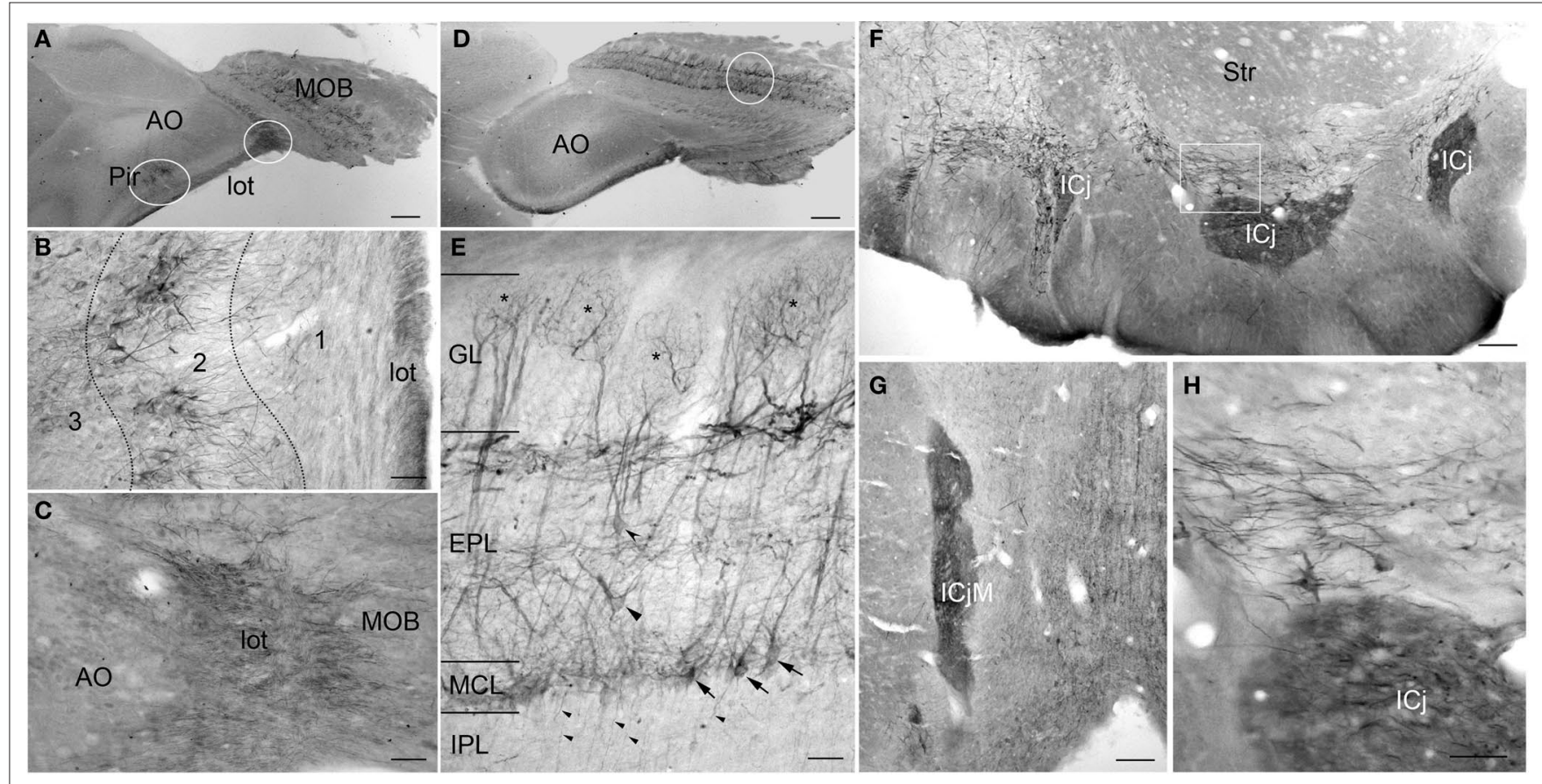

FIGURE 3 | PlexinA4 in the olfactory bulbs and Island of Calleja. (A) LoW magnification of a sagittal section through the piriform cortex and olfactory bulb immunostained for PlexinA4. The outlined regions are shown in higher magnification in B and C. (B) Micrograph of PlexinA4 labeling in the piriform cortex showing PlexinA4 positive pyramidal neurons in layer 2 as well as positive fibers coursing through the lateral olfactory tract (lot). (C) Micrograph showing intense fiber staining in the lot. (D) Low magnification of a sagittal section through main olfactory bulb (MOB) immunostained for PlexinA4. (E) Micrograph showing the region outlined in D. PlexinA4 is found in the mitral cells (arrows) and their dendrites surrounding the necklace glomeruli $\left({ }^{*}\right)$, and in the external (curved arrowhead) and middle (flat arrowhead) tufted neurons. PlexinA4 was also seen in the axons leaving the MOB through the internal plexiform layer (IPL; small arrowheads). (F) Coronal section through the accumbens region. Intense PlexinA4 neuropil staining is visible in the Islands of Calleja (ICj). The outlined area is shown at higher magnification in $\mathrm{H}$. (G) PlexnA4 positive neuropil in the major Island of Calleja (ICjM). (H) PlexinA4 is seen in the neuropil of the ICj and in neuronal cells bodies and large fibers dorsal to the Islands. $\mathrm{AO}$, anterior olfactory nucleus; EPL, external plexiform layer; GL, glomerular layer; ICj, Island of Calleja; ICjM, major Island of Calleja; IPL, internal plexiform layer; lot, lateral olfactory tract; $\mathrm{MCL}$, mitral cell layer; $\mathrm{MOB}$, main olfactory bulb; Pir, piriform cortex; Str, striatum. Scale bars: (A,D) 1 mm, (B,C,E) $80 \mu \mathrm{m}, \mathbf{( F , G ) ~} 100 \mu \mathrm{m}$, (H) $50 \mu \mathrm{m}$. the lateral posterior thalamic nuclei (LPMC; Figures 7A,B) and numerous moderately stained fibers were present in the dorsal lateral geniculate (DLG) and ventral lateral geniculate nuclei (VLG; Figures 7A,C,D). PlexinA4-labeled neurons were numerous in the dorsal (DZI) and ventral zona incerta (VZI; Figures 7E,G,H) and labeled processes could be observed encircling the mammillothalamic tract. Only a few labeled cell bodies and processes were seen in the more ventral subincertal nucleus. More posteriorly, lightly stained neurons and fibers were observed in the subthalamic nucleus (STN; Figures 7E,I). PlexinA4-immunoreactive fibers were also visible coursing through the medial leminiscus (ml; Figures 7E,J). The reuniens nucleus exhibited light PlexinA4 immunoreactivity in a few cell bodies and fibers. The parafascicular, lateral habenular, and reticular thalamic nuclei contained numerous large caliber PlexinA4-positive fibers, and the medial habenula contained a few lightly immunoreactive cell bodies (Figures 7K,L).

\section{CeREBelLuM}

In the cerebellum, PlexinA4 was present in the neurons of the interposed (IntA) and medial cerebellar (Med) nuclei (Figure 8A). Purkinje cells throughout the cerebellar cortex showed intense staining, whereas the granule cell layer $(\mathrm{gcl})$ was relatively lightly immunoreactive (Figure 8B). Individual PlexinA4- immunoreactive neurons contained reaction product primarily in their perikarya and proximal dendrites (Figures $\mathbf{8 C}, \mathbf{D}$ ). In the most intensely labeled neurons, however, extensive labeling of dendritic trees and proximal axon segments was also evident (Figure 8D).

\section{MIDBRAIN}

In the midbrain, PlexinA4 immunoreactivity was most pronounced in both superior (SC) and inferior colliculi (IC), substantia nigra $(\mathrm{SN})$, red nucleus $(\mathrm{RN})$, and several motor nuclei. The highest density of PlexinA4-immunoreactive cell bodies was observed in the deep gray layer of the SCSC, although these cell bodies were only lightly immunoreactive (Figure 9A). The superficial gray layer of the SC ( $\mathrm{SuG}$ ) contained many visibly stained fibers (Figure 9D), while the intermediate (InG) and deep gray layers of the SC contained a high number of strongly stained fibers and moderately immunopositive somata (Figure 9E). In the white layers of the SC, only a few lightly stained cell bodies were visible along with some immunoreactive fibers.

The IC, in layers 2 and 3 of both the external cortex (ECIC) (Figure 9B) and the dorsal cortex (DCIC), contained many PlexinA4 positive cell bodies and fibers. Layer 1 of the ECIC contained a high number of lightly stained fibers. Another point of interest was the 

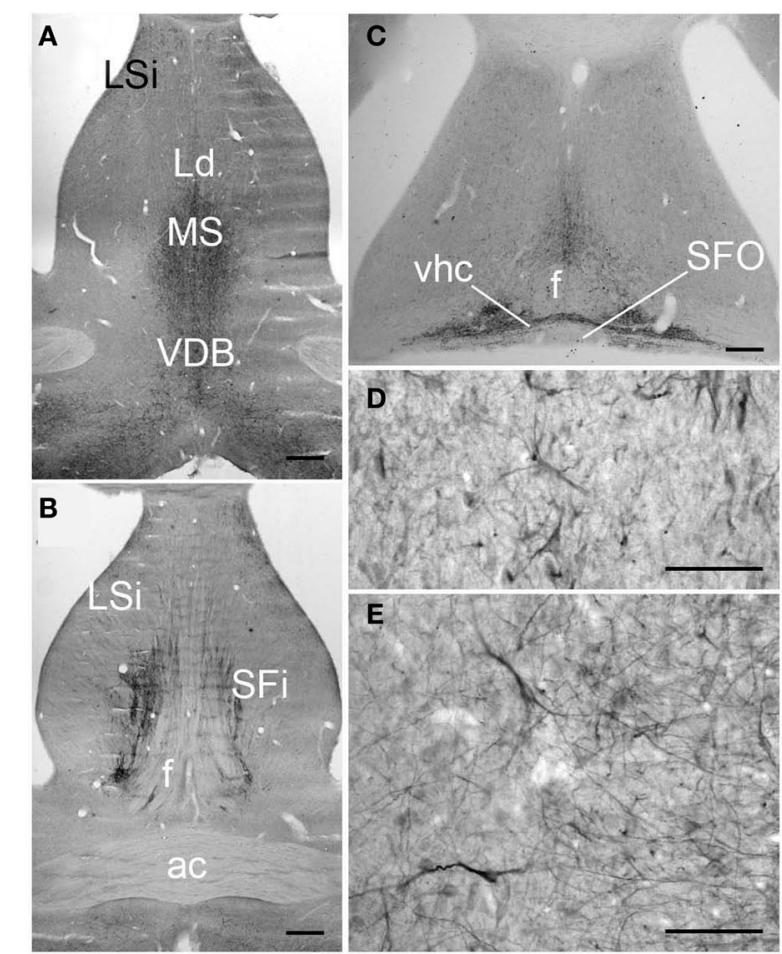

FIGURE 4 | PlexinA4 in septum and hippocampal formation. (A-C)

Micrographs of coronal (A-B) and horizontal (C) sections immunostained for PlexinA4. PlexinA4 is visible in neurons and fibers in the medial septum (MS), the intermediate part of the lateral septal nuclei (LSi; $\mathbf{D})$, the vertical limb of the diagonal band (VDB; E), the septofimbrial nuclei (SFi). PlexinA4 was also present in the ventral hippocampal commissure (vhc; $\mathbf{C})$. (F-J) Micrographs of coronal sections through the adult rat hippocampus stained for PlexinA4. PlexinA4 reaction product

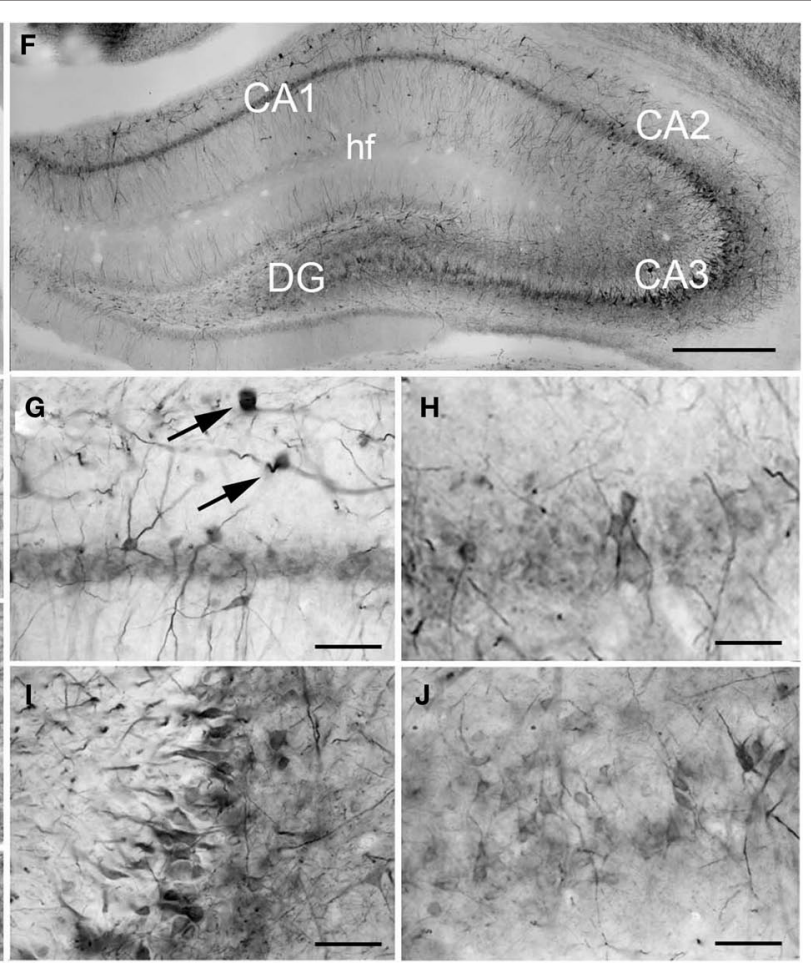

was present in the pyramidal cell bodies in CA1 (G), CA2 (H), CA3 (I) layers and in the dendate gyrus (DG; J). Staining was also found in interneurons in the stratum oreans (arrows in G). ac, anterior commissure; DG, dentate gyrus; f, fornix; hf, hippocampal fissure; Ld, lambdoid septal zone; LSi, intermediate part of the lateral septal nucleus; MS, medial septum; SFi, septofimbrial nucleus; SFO, subfornical organ; VDB, vertical limb of the diagonal band; vhc, ventral hippocampal commissure. Scale bars: (A-C, F) $500 \mu \mathrm{m},(\mathbf{D}, \mathbf{E}, \mathbf{G}-\mathbf{J}) 100 \mu \mathrm{m}$. central nucleus of the IC (CIC), which showed numerous coursing fibers and strongly immunoreactive somata (Figure 9C), and the nucleus of the brachium, which contained no stained cell bodies but did show a high number of PlexinA4 positive fibers.

Intense PlexinA4 staining of cell bodies and fibers was detected in the substantia nigra pars reticulata ( $\mathrm{SNr}$; Figures 9F, J) but was not present in the tyrosine hydroxylase expressing neurons of the substantia nigra pars compacta (SNpc on adjacent sections (Figures 9F,K), similar to our previous findings (Torre et al., 2010). There was no staining of VTA neurons or fibers. PlexinA4 was also present in the neurons and dendrites of the RN (Figures 9F,I) consistent with previous PlexinA4 mRNA observations (Spinelli et al., 2007). Dorsal to the RN, strong PlexinA4 immunoreactivity was visible in the oculomotor nuclei ( $3 \mathrm{~N}$ in Figures $\mathbf{9 F}, \mathbf{H}$ ) and could also be seen caudally in the adjacent trochlear nuclei $(4 \mathrm{~N}$ in Figure 9G) as well as in myelinated axon bundles of the medial longitudinal fasciculus (mlf; Figures 9G,H).

\section{PONS}

In the pons, the most intense PlexinA4 immunoreactivity was seen in cells bodies of the neurons of the mesencephalic trigeminal nucleus (Me5) and in their processes in the mesencephalic trigeminal tract (me5; Figure 10B). Other moderately immunoreactive neurons were present in the facial nucleus (7N; Figure 10E), lateral vestibular nucleus (LVe; Figure 10G), anterior tegmental nucleus (ATg; Figures 10H,J) and dorsal tegmental nucleus (DTg; Figure 10K). Both the motor (Mo5) and principal sensory $(\operatorname{Pr} 5)$ trigeminal nuclei contained an intermediate number of fibers, which were moderately PlexinA4-immunoreactive, but no cell bodies were detected in Pr5 while many stained neurons were observed in Mo5 (Figure 10D). The 7N and ambiguous (Amb) nuclei both contained intermediate numbers of cell bodies and fibers that were moderately stained (Figures 10A,E). PlexinA4positive facial nerve fibers were noticeable throughout the facial nerve (7n; Figures 10C,F).

PlexinA4-immunostaining was evident in cross-sections of large caliber fibers in the medial longitudinal fasciculus (mlf; Figures 10H,I). PlexinA4-immunoreactive cell bodies and fibers were also found in the pontine nuclei (Pn; Figure 10A), pontine reticular nucleus $(\mathrm{PnR})$, and abducens nucleus $(6 \mathrm{~N})$. Cell bodies in the PnR and $6 \mathrm{~N}$ were strongly PlexinA4-immunoreactive, while Pn neurons were only lightly stained. Conversely, the fibers observed in the Pn and PnR were moderately stained, while the fibers in $6 \mathrm{~N}$ were strongly stained. In the most ventral region of the pons, the transverse fibers of the pons showed PlexinA4 immunoreactivity. Finally, a few lightly stained cell bodies and fibers were also present in the periaqueductal gray and locus coeruleus (data not shown). 

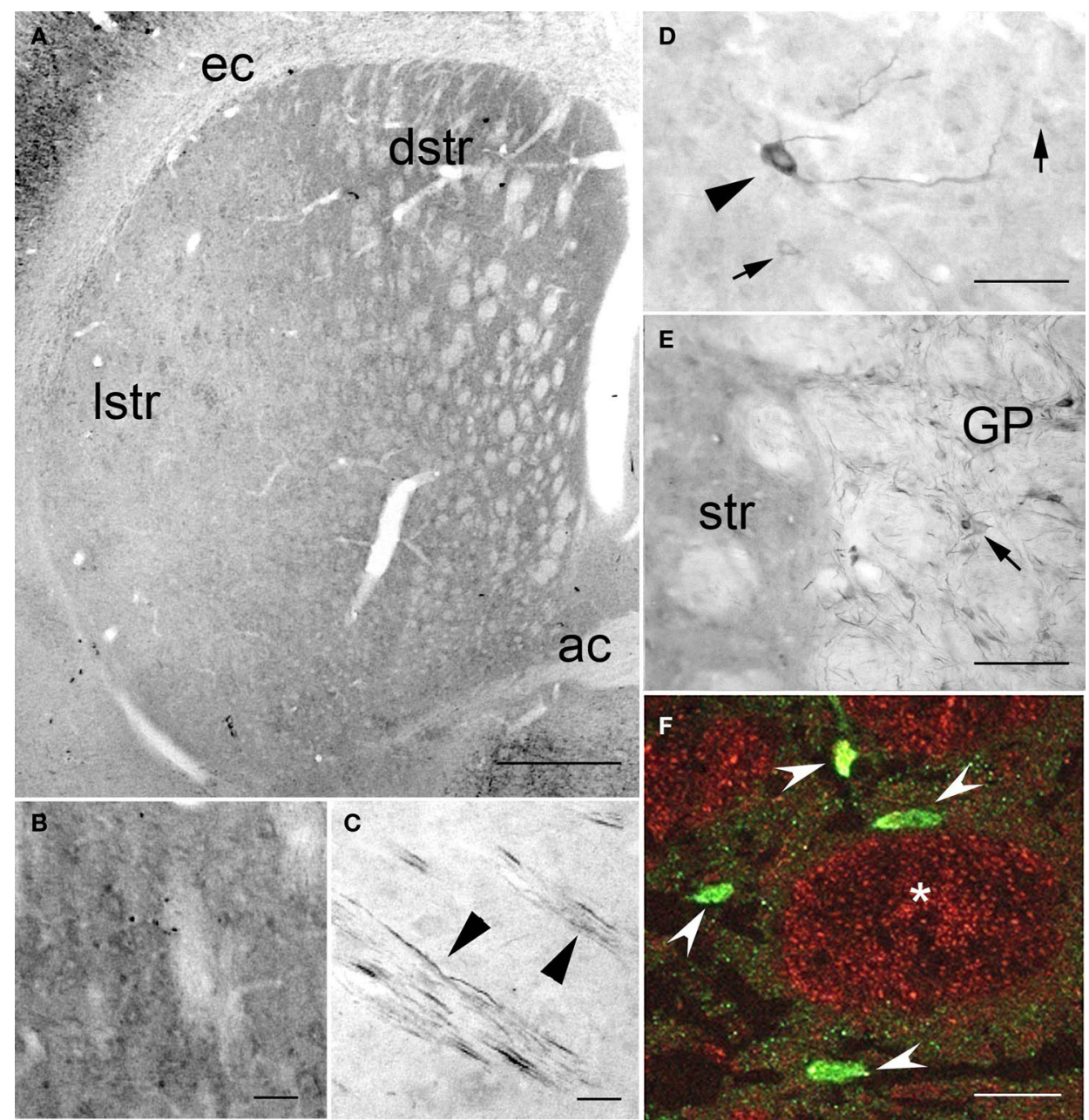

FIGURE 5 | PlexinA4 in the basal ganglia. (A-F) Micrographs of coronal sections through the striatum immunostained for PlexinA4. PlexinA4 immunoreactivity is highest in the neuropil in the dorsal striatum (B) and in cortico-striatal fibers in the lateral striatum (arrowheads in C). In the ventral lateral region of the striatum PlexinA4 immunoreactive product was visible in numerous but only lightly stained medium size neurons (arrows in D) and a few scattered large neurons (arrowhead in D). PlexinA4 was also present in neurons (arrow) and fibers in the globus pallidus (E). (F) Micrograph of a coronal section through the striatum co-labeled with PlexinA4 (red) and NeuN (green). Whereas NeuN is mostly seen in neurons and fine neuropil (arrowheads), PlexinA4 is visible in the neuropil and in large myelinated axons in cross sections of Wilson's pencils (*). ac, anterior commissure; dstr, dorsal striatum; ec, external capsule; GP, globus pallidus; Istr, lateral striatum; str, striatum. Scale bars: (A) $1 \mathrm{~mm}$, (B-E) $100 \mu \mathrm{m}$, (F) $50 \mu \mathrm{m}$

\section{MEDULLA}

Most evident in the medulla was the large number of PlexinA4-immunostained fibers and a few strongly stained motor nuclei. Large immunostained fibers were present in the spinal trigeminal tract (sp5), the inferior cerebellar peduncle (icp; Figure 11G), the medial lemniscus (ml; Figure 11K), the tectospinal tract and the mlf. Smaller caliber fibers stained for PlexinA4 were visible dorsally in the cuneate fasciculus (cu; Figure 11F) and ventrally in the pyramidal decussation and pyramidal tract (pyr; Figures 11A, I,K). In addition to fibers, PlexinA4 also labeled neurons in the gigantocellular reticular field and the lateral reticular nucleus, the lateral superior olive and the inferior olive (IO; Figures 11I,J). PlexinA4-positive neurons were also present in several motor nuclei including the dorsal motor nucleus of the vagus nerve, the hypoglossal nucleus (12N; Figures 11A-C) and the interpolar part (Sp5I;
Figure 11G) and the caudal part of the spinal trigeminal nucleus (Sp5c; Figure 11A). The dorsal motor nucleus of the vagus nerve contained very few immunoreactive cell bodies and fibers, and those that were present were only lightly stained. In contrast, the hypoglossal nucleus contained more immunoreactive cell bodies and fibers than the vagus. PlexinA4-labeled neurons were also present in the gracilis nucleus (Gr; Figures 11A,D) and cuneate nucleus $(\mathrm{Cu}$; Figures 11A,E).

\section{SPINAL CORD}

In the cervical spinal cord, PlexinA4-immunolabeling was found in neurons in both dorsal and ventral horns (Figures 12A-D,G). However, we consistently observed more PlexinA4-positive neurons in the ventral horn, and their morphology, size, and location were consistent with them being either motor neurons or interneurons (Figures 12C,G). PlexinA4-labeling was also present 

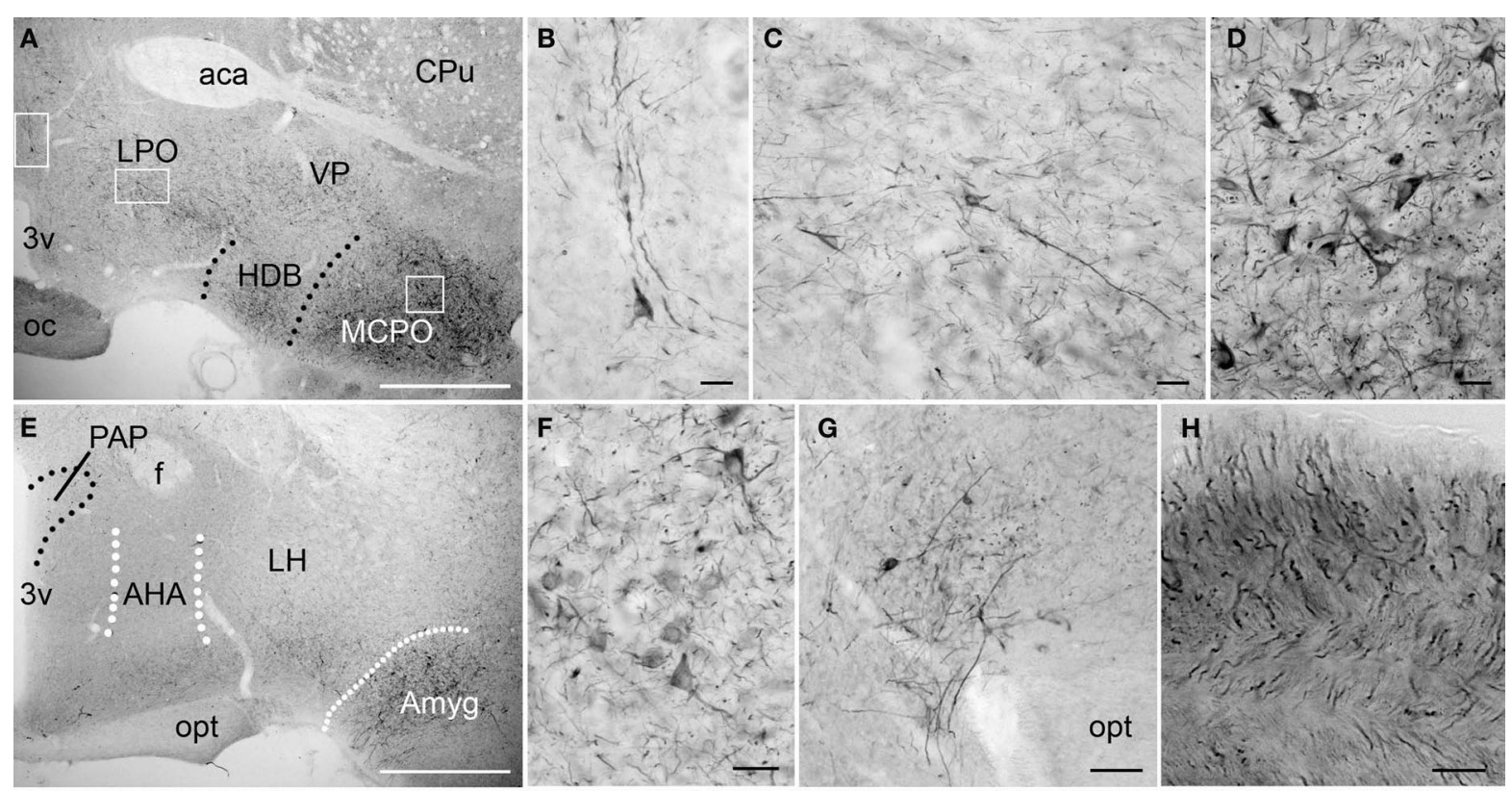

G
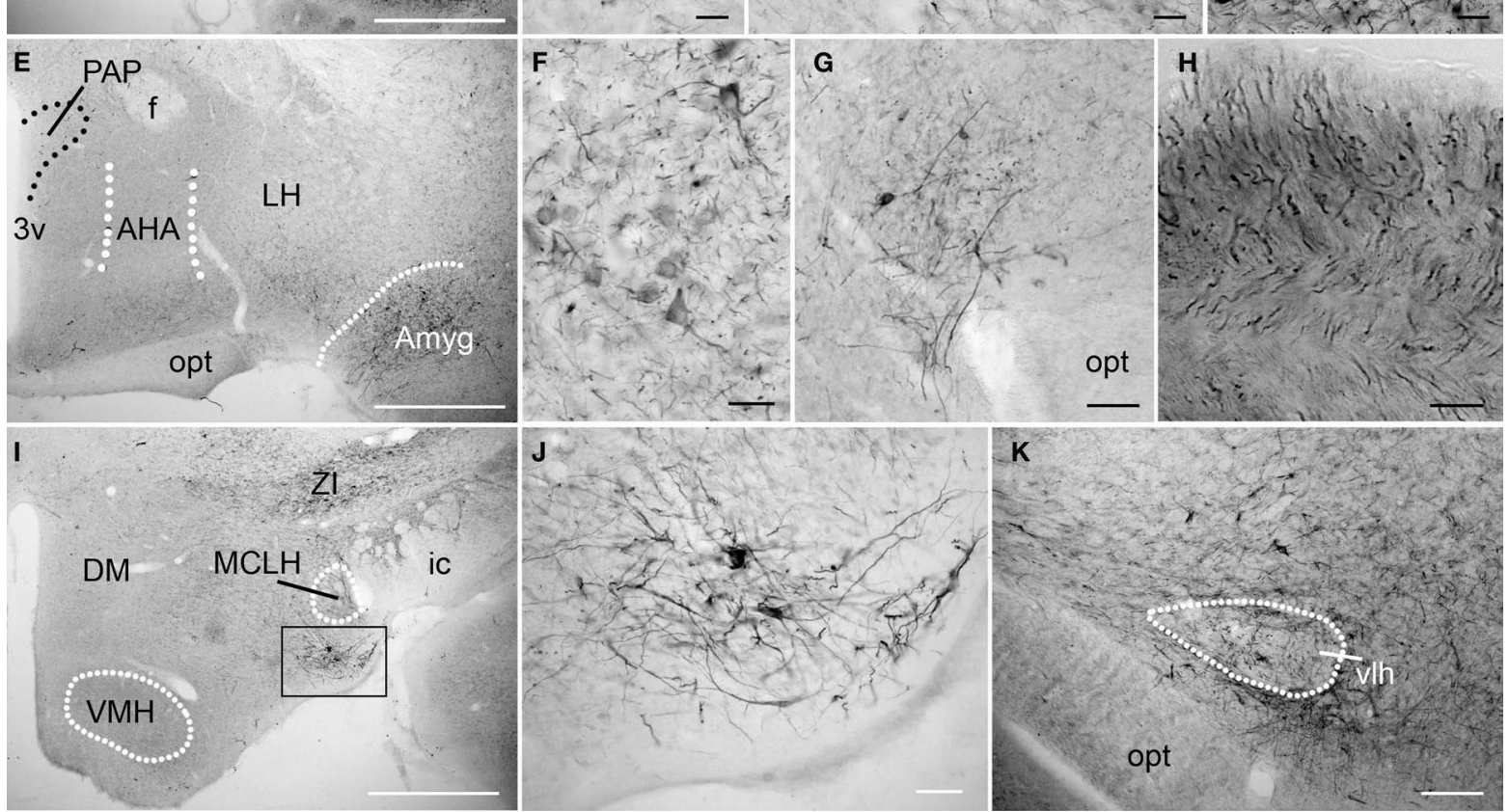

FIGURE 6 | PlexinA4 in the amygdala and the hypothalamus. Micrographs of the hypothalamic and amygdala region in coronal sections. In the anterior region of the hypothalamus (A-H), PlexinA4 is found in scattered neurons and large caliber processes in the preoptic area $(\mathbf{A}, \mathbf{B})$, the lateral preoptic area (LPO; $\mathbf{A}$ and C) and in the magnocellular preoptic nucleus (MCPO; $\mathbf{A}$ and D). Labeled axons are also visible in the optic chiasm (oc; $\mathbf{H}$ ). More posterior, PlexinA4 staining is present in neurons of the amygdala (E and $\mathbf{F}$ ) and in a region immediately dorsolateral to the optic tract (opt; $\mathbf{E}$ and $\mathbf{G}$ ). No PlexinA4 was detected in the dorsomedial (DM) and ventromedial hypothalamus ( $\mathrm{VMH}$; I) but strong labeling was seen in neurons and processes in a small nucleus medial to the internal capsule (ic) and ventral to the magnocellular nucleus of the lateral hypothalamus
(MCLH) visible in I and at higher magnification in $\mathbf{J}$. PlexinA4 positive processes were also visible dorsal to the opt around the ventrolateral hypothalamic tract (vlh; K). 3v, third ventricle; aca, anterior part of the anterior commissure; AHA, anterior hypothalamic area; Amyg, amygdala; CPu, caudate putamen; DM, dorsomedial hypothalamus; $f$, fornix; HDB, nucleus of the horizontal limb of the diagonal band; ic, internal capsule; LH, lateral hypothalamus; LPO, lateral preoptic area; MCLH, magnocellular nucleus of the lateral hypothalamus; MCPO,

magnocellular preoptic nucleus; oc, optic chiasm; opt, optic tract; PAP, anterior part of the paraventricular hypothalamic nucleus; vlh, ventrolateral hypothalamic tract; VMH, ventromedial hypothalamus; VP, ventral pallidum; ZI, zona incerta. Scale bars: (A,E,I) 1 mm, (B-D,F-H,J) $50 \mu \mathrm{m}$, (K) $100 \mu \mathrm{m}$. in motor axons exiting through the ventral roots (Figure $\mathbf{1 2 H}$ ). There was widespread labeling of ascending and descending white matter tracts. PlexinA4 was evident in cross-sections of large caliber fibers in the cuneate fasciculus (Figure 12E) and the ventral funiculus (Figure 12I) and in small caliber fibers in the ventral cuneate fasciculus (Figure 12F) and the gracilus fasciculus (Figure 12E). PlexinA4 was not detected in the dorsal horn substantia gelatinosa.

\section{DISCUSSION}

The present study provides the first description of PlexinA4 protein distribution in the adult rat CNS using a recently developed and commercially available polyclonal antibody directed to the C-terminal sequence of mouse PlexinA4. Our results include several major findings concerning the cellular distribution of PlexinA4. We found PlexinA4 to be expressed throughout the brain of the adult rat, with highest levels in the cortex, hippocampus, brainstem, pontine and medullary nuclei and moderate levels in particular forebrain and midbrain nuclei. PlexinA4 is present in neurons as well as small and large caliber fibers in many brain regions, but it does not appear to be expressed by glial cells. Within neurons, the PlexinA4 protein has a cytoplasmic localization and is found in the soma as well as in both dendrites and axons with no detectable nuclear labeling. In the cytoplasm, PlexinA4 immunoreactive product associates mostly with perinuclear structures as well as small puncta, and it outlines the membranes of neurons; such labeling is consistent with that of a membrane protein. 


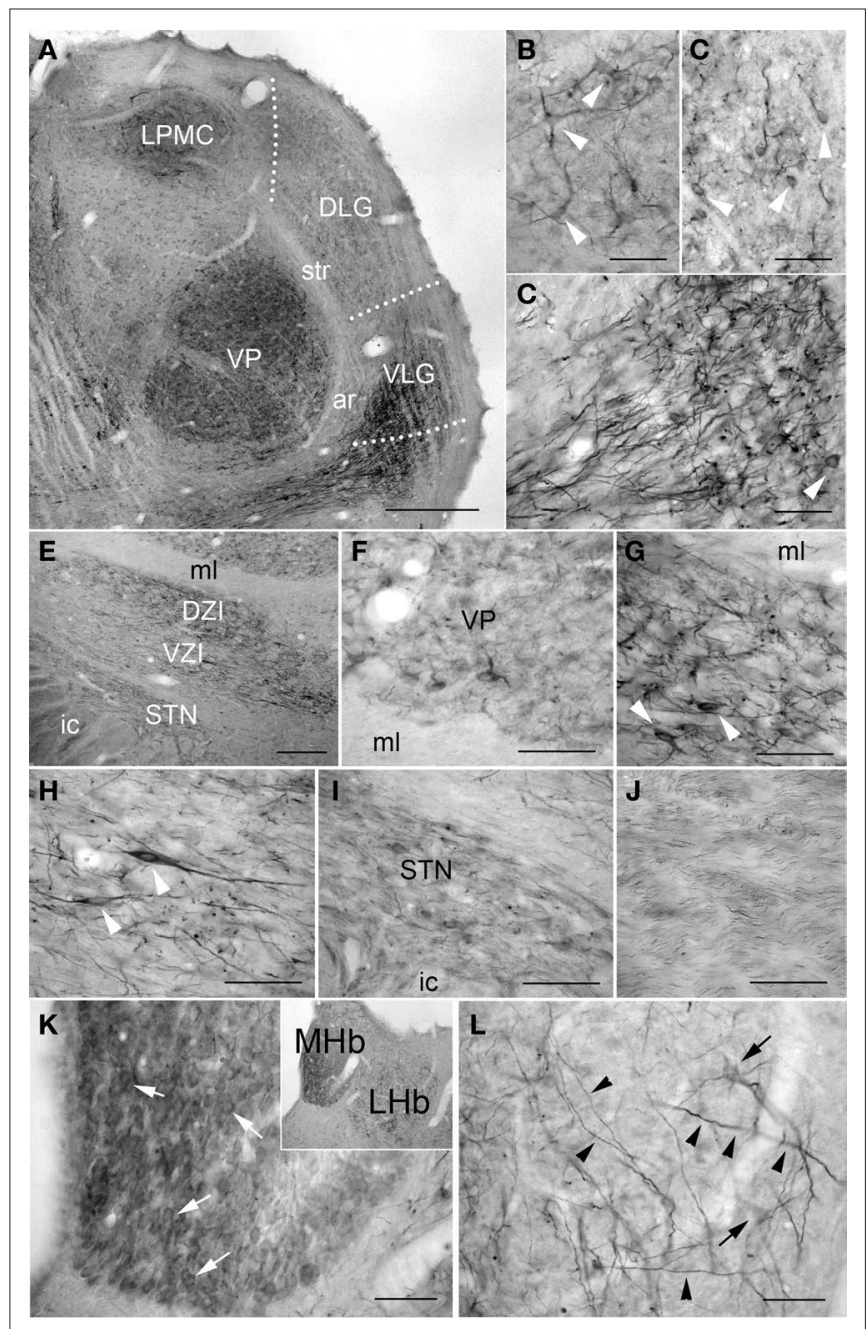

FIGURE 7 | PlexinA4 in thalamus, subthalamus and habenula. (A) Coronal section stained for PlexinA4 and photographed at low magnification. PlexinA4 is present in neurons (arrows) and fibers in several thalamic nuclei including the medio-caudal portion of the lateral posterior thalamic nucleus (LPMC; B) and the ventro-postero-thalamic nucleus (VP; F). Neurons and fibers stained for PlexinA4 are also found in the dorsal lateral (DLG) and ventral lateral geniculate nuclei (VLG; arrows in $\mathbf{C}$ and $\mathbf{D}$ respectively). (E) A low magnification micrograph of the zona incerta region. PlexinA4 immunoreactivity was also seen in neurons and fibers in both the dorsal (DZI; G) and ventral (VZI; H) zona incerta. Lighter labeling was seen in the subthalamic nucleus (STN; I) and in the axons coursing through the medial lemniscus ( $\mathrm{ml}$; J). Strong PlexinA4 expression was also seen in both the medial $(\mathrm{MHb})$ and the lateral habenula $(\mathrm{LHb})$ with lightly stained but numerous PlexinA4 positive neurons in the $\mathrm{MHb}$ (arrowheads in $\mathbf{K}$ ) and a few positive neurons (arrows) and many fibers (arrowheads) in the LHb (L). DLG, dorsal lateral geniculate nucleus; ar, acoustic radiation; DZI, dorsal zona incerta; ic, internal capsule; LHb, lateral habenula; LPMC, medio-caudal portion of the lateral posterior thalamic nucleus; $\mathrm{MHb}$, medial habenula; ml, medial lemniscus; STN, subthalamic nucleus; str, superior thalamic radiation; VLG, ventral lateral geniculate nucleus; VP, ventral postero thalamic nucleus; VZI, ventral zona incerta. Scale bars: (A) 1 mm, (B-D,F-L) $100 \mu \mathrm{m}$, (E) $200 \mu \mathrm{m}$.

\section{COMPARISON WITH PREVIOUS PLEXINA4 MRNA DISTRIBUTION AND KNOCKOUT STUDIES}

The PlexinA4 protein distribution in the adult rat brain aligns well with what is known of the distribution of PlexinA4 mRNA

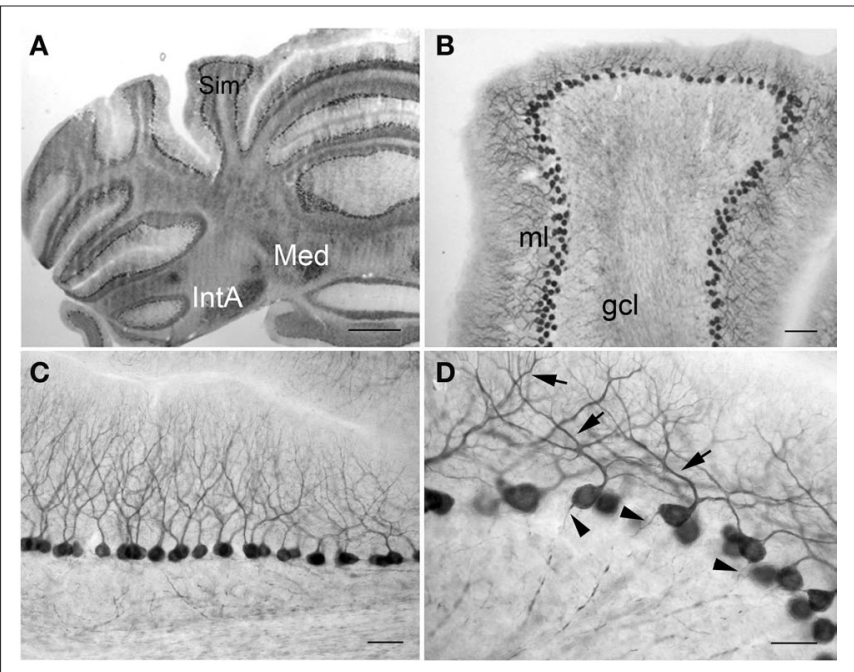

FIGURE 8 | PlexinA4 in the cerebellum. Micrographs of coronal (A,B) and sagittal (C,D) sections through the adult rat cerebellum stained for PlexinA4. PlexinA4 is present in the Purkinje cell soma, dendrites (arrows in D) and axons (arrowheads in D) throughout the cerebellum. Neurons in the medial cerebellar nucleus and anterior interposed cerebellar nucleus also express PlexinA4 (A). gcl, granule cell layer; IntA, anterior interposed cerebellar nucleus; Med, medial cerebellar nucleus; ml, molecular layer; Sim, simple lobule. Scale bars: (A) 1 mm, (B) $200 \mu \mathrm{m}$, (C) $100 \mu \mathrm{m}$, (D) $50 \mu \mathrm{m}$.

transcripts (Suto et al., 2003; Perala et al., 2005; Runker et al., 2008) as well as with the few reports of protein distribution in the adult mouse (Spinelli et al., 2007) and anomalies seen in the PlexinA4 knockout animals (Suto et al., 2005, 2007; Low et al., 2008; Runker et al., 2008; Schwarz et al., 2008). Accordingly, PlexinA4 proteins were detected in most cortical areas where mRNA had been detected in neurons of layer $V$ in various cortical regions including primary motor and visual cortex in postnatal mice (Low et al., 2008; Runker et al., 2008). Our finding of PlexinA4 in pyramidal neurons in layer $\mathrm{V}$ of cortex and in the cuneatus nuclei at the level of the spinal cord confirms a role in the corticospinal tract where plexins have previously been shown to participate in the pruning (Low et al., 2008) and proper guidance (Runker et al., 2008) of the developing corticospinal tract at the level of the caudal medulla and at the pyramidal decussation. Also consistent with its presence in the axons of cortical neurons, PlexinA4 immunolabeling was seen in the corpus callosum and external capsule.

The anterior commissure is comprised of axons from the olfactory bulbs as well as axons from several cortical areas. In PlexinA4 knockout mice, the anterior commissure is reduced in size and defasciculated (Suto et al., 2005; Yaron et al., 2005). However, although we found many PlexinA4 positive cortical neurons in the adult rat brain, there was no detectable expression of PlexinA4 in the anterior commissure. Therefore, it is possible that PlexinA4 is expressed in axons destined for the anterior commissure only during development and, over time, the expression is downregulated. Alternatively, this observation might be accounted for by a species difference or limitations set by the available antibodies. 


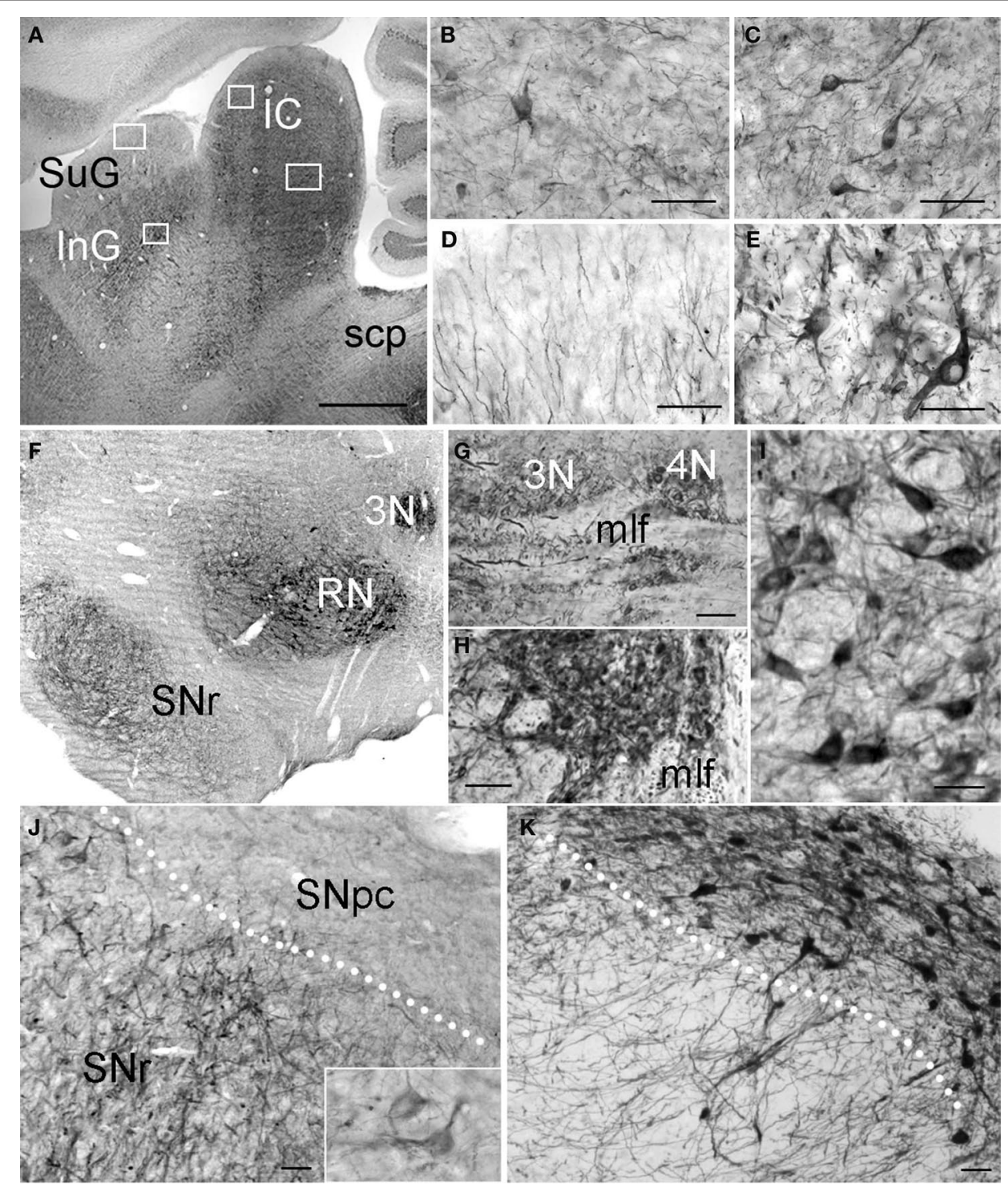

FIGURE 9 | PlexinA4 in the midbrain. Micrographs of sagittal (A-E and $\mathbf{G})$ and coronal (F,H-K) sections through the adult rat midbrain immunostained for PlexinA4 (A-J) or tyrosine hydroxylase (K). PlexinA4 reaction product is seen in many neurons in both the inferior (IC) and superior colliculi (SC; $\mathbf{A}-\mathbf{E})$. In the IC, immunoreactive cell bodies and fibers are present in the external cortex (ECIC; B) and the central nucleus $(\mathrm{CIC}$; $\mathbf{C})$. In the SC, labeled fibers are visible in the superficial gray layer (SuG; D) whereas immunoreactive neuronal cell bodies and fibers are present in the deep gray layer (E). PlexinA4 staining was also present in neurons in the oculomotor ( $3 \mathrm{~N} ; \mathbf{F}-\mathbf{H})$ and throchlear nuclei $(4 \mathrm{~N} ; \mathbf{F}$ and $\mathbf{G}), \mathrm{RN}$
( $\mathbf{F}$ and $\mathbf{I}$ ) and in neurons and fibers of the substantia nigra pars reticulata (SNr; $\mathbf{F}$ and $\mathbf{J}$ ). Insert in $\mathbf{J}$ shows higher magnification view of PlexinA4 positive cells in the SNr. PlexinA4 is not expressed by the tyrosine hydroxylase-positive dopaminergic neurons of substantia pars compacta (SNpc; K). $3 \mathrm{~N}$, oculomotor nucleus; 4N, trochlear nucleus; IC, inferior colliculus; InG, intermediate gray layer of the superior colliculus; mlf, medial longitudinal fasciculus; RN, red nucleus; scp, superior cerebellar peduncle; SNpc, substantia nigra pars compacta; SNr, substantia nigra pars reticulata; SuG, superficial gray layer of the superior colliculus. Scale bars: (A and F) 1 mm, (B-E,G-H) $100 \mu \mathrm{m}$, (I-K) $50 \mu \mathrm{m}$.
PlexinA4 protein was present in the dentate granule cells and the CA3 pyramidal cells of the hippocampus where in situ hybridization (ISH) analyses on P1 mice revealed strong signals for PlexinA4 transcripts (Suto et al., 2007). Although PlexinA4 protein has been immunodetected in the suprapyramidal and infrapyramidal bundles of mossy fibers and in the dentate hilus in P1 and P10 mice (Suto et al., 2007) this type of staining was not visible in the adult rat hippocampus. It is conceivable that PlexinA4 expression in these areas is developmentally regulated and therefore undetectable in the adult brain. Developmental regulation of axon guidance molecules has been documented by others (Yu and Bargmann, 2001; Tsim et al., 2004). Another possibility is that the discrepancy in staining represents differences between species; however, we have unpublished data indicating similar PlexinA4 expression patterns in both adult mouse and rat hippocampus.

Consistent with the findings that PlexinA4 transcripts are detected in a subset of motor neurons and motor nuclei of the brainstem in the developing mouse brain (Suto et al., 2003), our results show PlexinA4 protein in large neurons in the ven- 

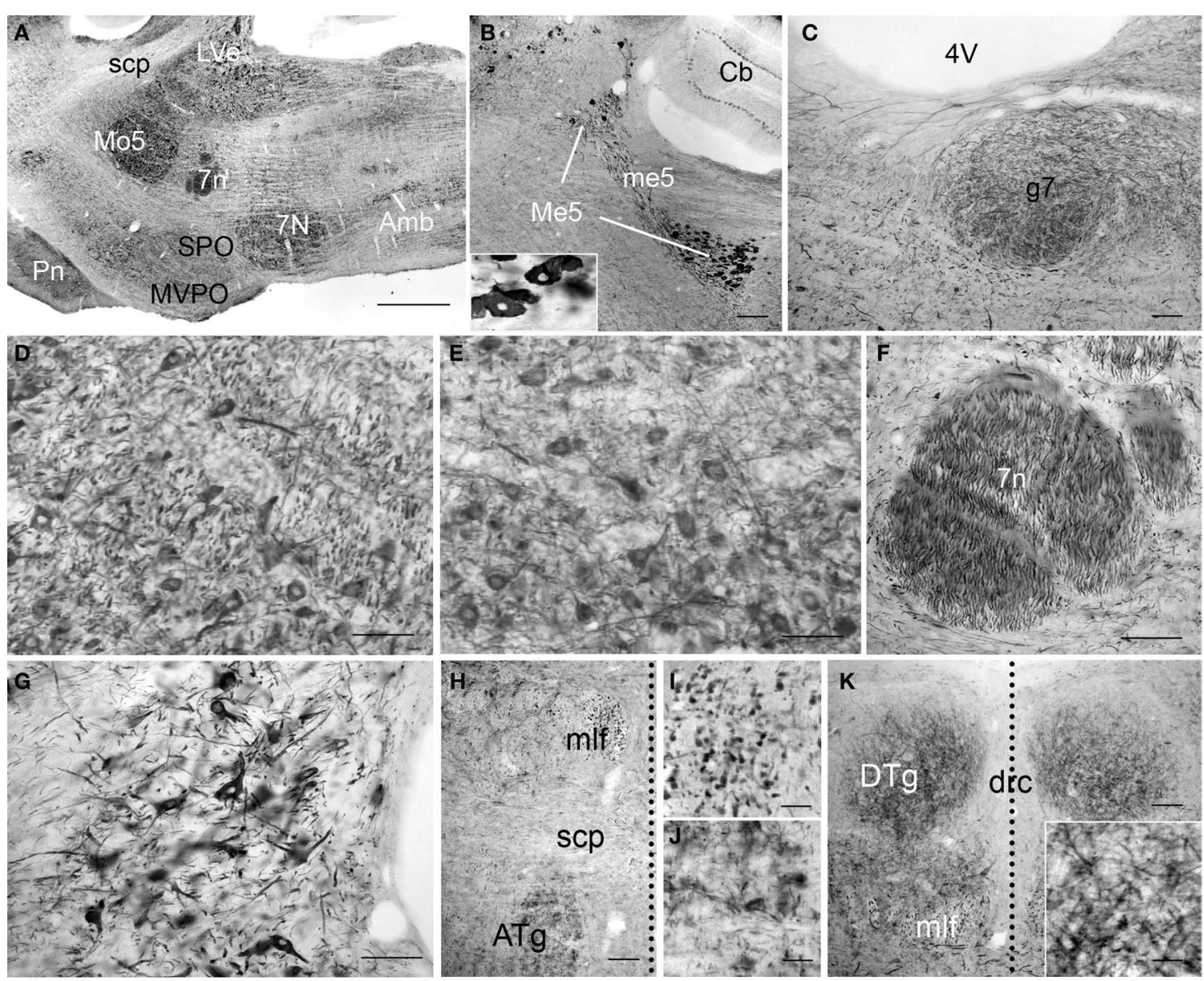

FIGURE 10 | PlexinA4 in the pons. Micrographs of sagittal (A-G) and coronal (H-K) sections through the adult rat pons immunostained for PlexinA4. PlexinA4 immunoreactive product is seen in neurons in the mesencephalic trigeminal nucleus (Me5; B), the motor trigeminal nucleus (Mo5; $\mathbf{A}$ and $\mathbf{D}$ ), the facial nucleus (7N; $\mathbf{A}$ and $\mathbf{E})$, the lateral vestibular nucleus (LVe; $\mathbf{A}$ and $\mathbf{G})$, the anterior tegmental nucleus (ATg; $\mathbf{H}$ and $\mathbf{J}$ ) and the dorsal tegmental nucleus (DTg; K). Insert in (B) shows a higher magnification view of PlexinA4 positive cell bodies in the Me5. Immunoreactive fibers were visible in the genu of the facial nerve (g7; C), the facial nerve (7n; $\mathbf{A}$ and $\mathbf{F}$ ) and the medial longitudinal fasciculus (mlf;
$\mathbf{H}$ and $\mathbf{I})$. In coronal sections, the midline is represented with a vertical dotted line. $4 \mathrm{~V}$, fourth ventricle; $7 \mathrm{n}$, facial nerve; $7 \mathrm{~N}$, facial nucleus; Amb, ambiguus nucleus; ATg, anterior tegmental nucleus; $\mathrm{Cb}$, cerebellum; drc, dorsal raphe nucleus; DTg, dorsal tegmental nucleus; g7, genu of the facial nerve; LVe, lateral vestibular nucleus; Me5, mesencephalic trigeminal nucleus; me5, mesencephalic trigeminal tract; mlf, medial longitudinal fasciculus; Mo5, motor trigeminal nucleus; MVPO,: medioventral periolivary nucleus; Pn, pontine nuclei; scp, superior cerebellar peduncle; SPO, superior paraolivary nucleus. Scale bars: (A) $1 \mathrm{~mm}$, (B) $200 \mu \mathrm{m}$, (C-H,K) $100 \mu \mathrm{m}$, (I-J) $50 \mu \mathrm{m}$. tral horn of the spinal cord as well as in neurons in the nucleus ambiguus, the facial nucleus, the motor trigeminal nucleus, the oculomotor nucleus, the hypoglossal nucleus and, to a lesser extent, the dorsal nucleus of the vagus. We also found PlexinA4 in the nerves originating from these nuclei. PlexinA4 protein expression in both the red nucleus and the facial nucleus coincides with results from a previous study where PlexinA4 mRNA was upregulated in these nuclei following axotomy of the rubrospinal pathway and facial nerve (Spinelli et al., 2007). The two PlexinA4 knockout lines generated thus far also present with defects in the trajectories of the cranial and spinal nerves despite normal position and configuration of the cranial and spinal ganglia (Suto et al., 2005).

PlexinA4 proteins were also found in labeled axons in Wilson's pencils in the striatum. These labeled axons could belong to various tracts including the cortico-striatal, cortico-spinal, or striato-fugal pathways, all of which travel via the Wilson's Pencils (Hersch et al., 1995; Prensa et al., 2000; Carter et al., 2008; Faulkner et al., 2008). Whereas PlexinA4 expression was strong in cortical neurons in layers II, III, VI, and in layer V, giving rise respectively to the corticostriatal and corticospinal tracts, PlexinA4 was not detected in the striatal medium spiny neurons where striatofugal projections originate. Evidence of PlexinA4 localization to corticospinal axons was presented in two previous studies. Defect in the dorsal turning and midline crossing of the corticospinal fibers at the pyramidal decussation were found in Sema6A and PlexinA4 knockout mice (Faulkner et al., 2008). Furthermore, mice lacking PlexinA4 show a reduced number of Nrp1-immunopositive corticospinal axons in the intermediate zone of the cerebral cortex and the internal capsule, and callosal axons fail to cross-over caudally and accumulate on the ipsilateral side (Bechara et al., 2008). 

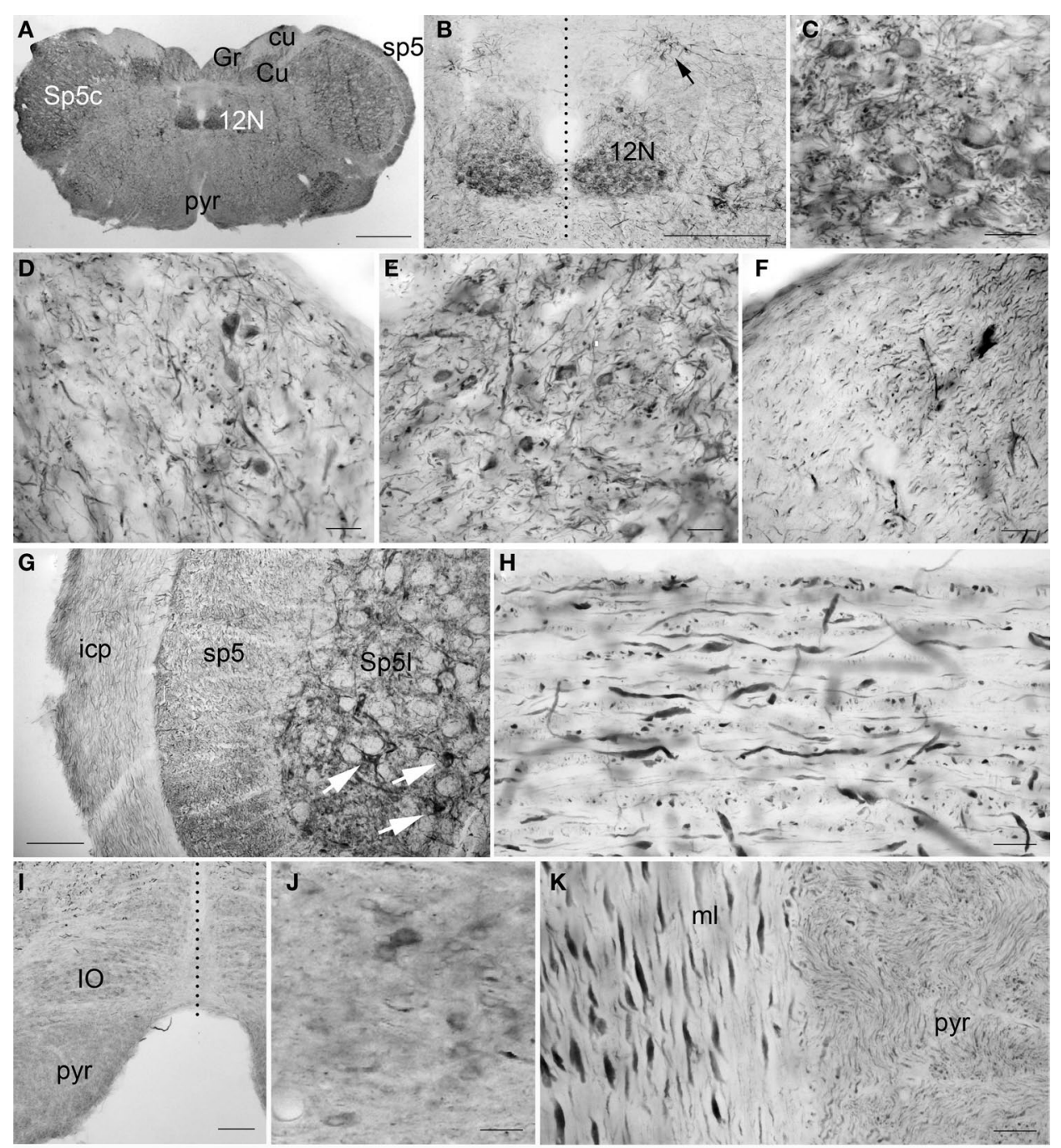

FIGURE 11 | PlexinA4 in the medulla. Micrographs of coronal (A-G and I-J), sagittal (H) and horizontal (K) sections through the adult rat medulla stained for PlexinA4. PlexinA4 neuronal staining is most intense in the hypoglossal nucleus $(12 \mathrm{~N} ; \mathbf{A}-\mathbf{C})$, the gracile nucleus ( $\mathrm{Gr} ; \mathbf{A}$ and $\mathbf{D})$, the cuneate nucleus (Cu; $\mathbf{A}$ and $\mathbf{E})$, the spinal trigeminal nucleus (Sp5; arrows in $\mathbf{G}$ ) and the A2 noradrenaline cell group (arrow in B). Less intense but visible labeling is also seen in the neurons of the inferior olive $(\mathrm{IO} ; \mathbf{I}$ and $\mathbf{J})$. Large caliber fibers positive for PlexinA4 are present in the inferior cerebellar peduncle (icp; $\mathbf{G})$, the spinal trigeminal tract (sp5; $\mathbf{G}$ and $\mathbf{H}$ ), and the medial lemniscus ( $\mathrm{ml} ; \mathbf{K})$. Fine labeled processes are also found in the cuneate (cu; $\mathbf{F}$ ) and pyramidal (pyr; K) tracts. $12 \mathrm{~N}$, hypoglossal nucleus; cu, cuneate fasciculus; $\mathrm{Cu}$, cuneate nucleus; $\mathrm{Gr}$, gracile nucleus; icp, inferior cerebellar peduncle; IO, inferior olive; $\mathrm{ml}$, medial lemniscus; pyr, pyramidal tract; sp5, spinal trigeminal tract; Sp5c, caudal part of the spinal 5 nucleus; Sp5l, interpolar part of the spinal 5 nucleus. Dashed vertical lines represent midline. Scale bars: (A) $1 \mathrm{~mm}$, (B) $500 \mu \mathrm{m}$, (C-F) $50 \mu \mathrm{m}$, (G) $100 \mu \mathrm{m}$, (H,J,K) $50 \mu \mathrm{m}$, (I) $200 \mu \mathrm{m}$.

\section{COMPARISON OF PLEXINA4 PROTEINS LOCALIZATION WITH INTERACTING PARTNERS}

The distribution of PlexinA4 protein in the adult CNS is comparable to that of the known distribution of its co-receptor Nrp1. Nrp1 is found in the developing cingulate cortex where it plays a role in guiding axons towards the midline (Hatanaka et al., 2009; Piper et al., 2009). Although this region has not been examined in PlexinA4 knockout mice, it is likely that the defects seen in Nrp1 knockout mice are transduced via Nrp1/PlexinA4 interaction. Loss of Sema3A/Nrp1 also causes defasciculation and ectopic projection of facial nerve axons (Schwarz et al., 2008), which is consistent with our observation that PlexinA4 is present in neurons of the facial nucleus and their projections in the facial nerve. Nrp1 is also found in adult spinal cord motor neurons where PlexinA4 protein is expressed at relatively high levels (Pasterkamp et al., 1999; De Winter et al., 2002b; Lindholm et al., 2004; Pasterkamp and Verhaagen, 2006).

We found PlexinA4 to be highly expressed in a subset of neurons of the olfactory bulb. This is consistent with earlier findings that Sema3A and its receptors and co-receptors participate in axon sorting and establishment of the olfactory map topography (Imai et al., 2009). Finally, we and others have suggested a critical role of semaphorins and their co-receptors in the development of the nigrostriatal pathway (Hernandez-Montiel et al., 2008; Kolk et al., 2009; Torre et al., 2010). It is interesting to note that although Nrp1 has been shown to be expressed in the dopaminergic neurons of 

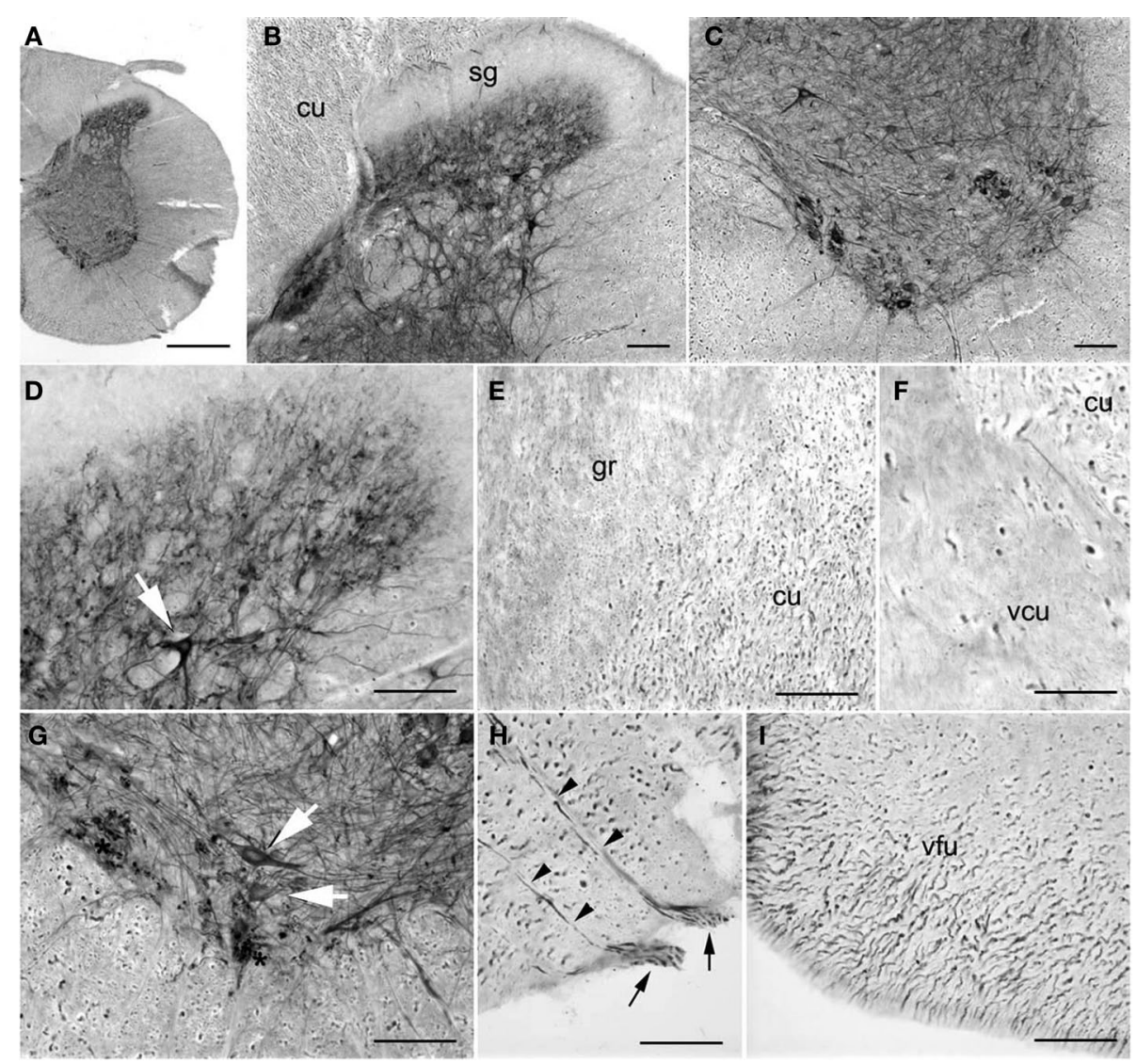

FIGURE 12 | PlexinA4 in spinal cord. Micrographs of coronal sections from an adult rat spinal cord stained for PlexinA4. PlexinA4 staining is visible in neurons (arrows) and fibers in the dorsal (B and D) and ventral (C and $\mathbf{G}$ ) horns. PlexinA4 positive axon bundles are mostly found in the dorsal part of the cuneate fasciculus (cu) region (E and $\mathbf{F}$ ) and the ventral funiculus (I)
PlexinA4 staining is present in motor neurons (arrows in $\mathbf{G}$ ) and their axons (arrowheads in $\mathbf{H}$ ) exiting the spine through their ventral roots (arrows in $\mathbf{H}$ ). $\mathrm{cu}$, cuneate fasciculus; gr, fasciculus gracilis; sg, substantia gelatinosa; vcu, ventral cuneate fasciculus; vfu, ventral funiculus. Scale bars: (A) $1 \mathrm{~mm}$, (B-I) $100 \mu \mathrm{m}$.

the embryonic ventral mesencephalic region (Hernandez-Montiel et al., 2008; Kolk et al., 2009; Torre et al., 2010), we only detected PlexinA4 protein in the substantia nigra pars reticulata. It is possible that PlexinA1, another co-receptor for Nrp1, rather than PlexinA4, is at play in the substantia nigra pars compacta.

\section{POTENTIAL ROLE OF SEMAPHORINS AND RECEPTORS AND CO- RECEPTORS IN ADULT BRAIN}

Over the past decade, several semaphorin family members and their receptors and co-receptors have been found to be expressed in the adult CNS. Increasing evidence indicates that in the adult these molecules contribute to the maintenance and stability of neuronal networks, as well as repairing and remodeling these networks (De Winter et al., 2002a; de Wit and Verhaagen, 2003; Pasterkamp and Verhaagen, 2006). These hypotheses are based on studies showing continuous expression of these molecules in adult stages and changes

\section{REFERENCES}

Barnes, G., Puranam, R. S., Luo, Y., and McNamara, J. O. (2003). Temporal specific patterns of semaphorin gene expression in rat brain after kainic acid-induced status epilepticus. Hippocampus 13, 1-20.

Bechara, A., Nawabi, H., Moret, F., Yaron, A., Weaver, E., Bozon, M., Abouzid, K., Guan, J. L., Tessier-Lavigne, M., in expression levels following injury or in the context of neurological diseases, as well as in response to physiological or pharmacological manipulation (Holtmaat et al., 2002; Barnes et al., 2003; Jassen et al., 2006; Mann et al., 2007). A more detailed analysis of adult PlexinA4 knockout animals, including histological and behavioral assessment, could further clarify the role of PlexinA4 in the mature brain. In addition, genetic manipulation of PlexinA4 using lentiviral or adenoviral delivery of PlexinA4 shRNA in precise CNS regions where PlexinA4 has been localized should provide a deeper insight into the mechanisms by which PlexinA4 signaling contributes to structural plasticity and regeneration in the adult brain.

\section{ACKNOWLEDGMENTS}

This work was supported by a grant from NIH (K08 NS4632201A1) to Robert E. Gross. Claire-Anne Gutekunst is funded in part by NIH (R03 NS58376-01A1).
Lemmon, V., and Castellani, V. (2008) FAK-MAPK-dependent adhesion disassembly downstream of L1 contributes to semaphorin3A-induced collapse. EMBO J. 27, 1549-1562.
Bussolino, F., Valdembri,D., Caccavari,F., and Serini, G. (2006). Semaphoring vascular morphogenesis. Endothelium 13, 81-91.

Carter, L. M., Starkey, M. L., Akrimi, S. F., Davies, M., McMahon, S. B., and 
Bradbury, E. J. (2008). The yellow fluorescent protein (YFP-H) mouse reveals neuroprotection as a novel mechanism underlying chondroitinase $\mathrm{ABC}$-mediated repair after spinal cord injury. J. Neurosci. 28, 14107-14120.

De Winter, F., Holtmaat, A. J., and Verhaagen, J. (2002a). Neuropilin and class 3 semaphorins in nervous system regeneration. Adv. Exp. Med. Biol. 515, 115-139.

De Winter, F., Oudega, M., Lankhorst, A. J., Hamers, F. P., Blits, B., Ruitenberg, M. J., Pasterkamp, R. J., Gispen, W. H., and Verhaagen, J. (2002b). Injuryinduced class 3 semaphorin expression in the rat spinal cord. Exp. Neurol. 175, 61-75.

de Wit, J., and Verhaagen, J. (2003). Role of semaphorins in the adult nervous system. Prog. Neurobiol. 71, 249-267.

Fallon, J. H., Riley, J. N., Sipe, J. C., and Moore, R. Y. (1978). The islands of Calleja: organization and connections. J. Comp. Neurol. 181, 375-395.

Faulkner, R. L., Low, L. K., Liu, X. B., Coble, J., Jones, E. G., and Cheng, H. J. (2008). Dorsal turning of motor corticospinal axons at the pyramidal decussation requires plexin signaling. Neural Dev. 3, 21 .

Fudge, J. L., and Haber, S. N. (2001). Bed nucleus of the stria terminalis and extended amygdala inputs to dopamine subpopulations in primates. Neuroscience 104, 807-827.

Hatanaka,Y., Matsumoto, T., Yanagawa,Y., Fujisawa, H., Murakami, F., and Masu, M. (2009).Distinct roles of neuropilin 1 signaling for radial and tangential extension of callosal axons. J. Comp. Neurol. 514, 215-225.

Hernandez-Montiel, H. L., Tamariz, E., Sandoval-Minero, M. T., and VarelaEchavarria, A. (2008). Semaphorins $3 \mathrm{~A}, 3 \mathrm{C}$, and $3 \mathrm{~F}$ in mesencephalic dopaminergic axon pathfinding. $J$. Comp. Neurol. 506, 387-397.

Hersch, S. M., Ciliax, B. J., Gutekunst, C. A., Rees, H. D., Heilman, C. J., Yung, K. K., Bolam, J. P., Ince, E., Yi, H., and Levey, A. I. (1995). Electron microscopic analysis of D1 and D2 dopamine receptor proteins in the dorsal striatum and their synaptic relationships with motor corticostriatal afferents. J. Neurosci. 15, 5222-5237.

Holtmaat, A. J., De Winter, F., De Wit, J., Gorter, J. A., da Silva, F. H., and Verhaagen, J. (2002). Semaphorins: contributors to structural stability of hippocampal networks? Prog. Brain Res. 138, 17-38.
Imai, T., Yamazaki, T., Kobayakawa, R., Kobayakawa, K., Abe, T., Suzuki, M., and Sakano, H. (2009). Pre-target axon sorting establishes the neural map topography. Science 325, 585-590.

Jassen, A. K., Yang, H., Miller, G. M., Calder, E., and Madras, B. K. (2006). Receptor regulation of gene expression of axon guidance molecules: implications for adaptation. Mol. Pharmacol. 70, 71-77.

Kolk, S. M., Gunput, R. A., Tran, T. S., van den Heuvel, D. M., Prasad, A. A., Hellemons, A. J., Adolfs, Y., Ginty, D. D., Kolodkin, A. L., Burbach, J. P., Smidt, M. P., and Pasterkamp, R. J. (2009). Semaphorin $3 \mathrm{~F}$ is a bifunctional guidance cue for dopaminergic axons and controls their fasciculation, channeling, rostral growth, and intracortical targeting. J. Neurosci. 29, 12542-12557.

Lindholm, T., Skold, M. K., Suneson, A. Carlstedt, T., Cullheim, S., and Risling, M. (2004). Semaphorin and neuropilin expression in motoneurons after intraspinal motoneuron axotomy. Neuroreport 15, 649-654.

Low, L. K., Liu, X. B., Faulkner, R. L., Coble, J., and Cheng, H. J. (2008). Plexin signaling selectively regulates the stereotyped pruning of corticospinal axons from visual cortex. Proc. Natl. Acad. Sci. U.S.A. 105, 8136-8141.

Mann, F., Chauvet, S., and Rougon, G. (2007). Semaphorins in development and adult brain: implication for neurological diseases. Prog. Neurobiol. 82, $57-79$.

Okada, A., Tominaga, M., Horiuchi, M., and Tomooka, Y. (2007). Plexin-A4 is expressed in oligodendrocyte precursor cells and acts as a mediator of semaphorin signals. Biochem. Biophys. Res. Commun. 352, 158-163.

Oliva, A. A. Jr., Jiang, M., Lam, T., Smith, K. L., and Swann, J. W. (2000). Novel hippocampal interneuronal subtypes identified using transgenic mice that express green fluorescent protein in GABAergic interneurons. J. Neurosci. 20, 3354-3368.

Pasterkamp, R. J., Giger, R. J., Ruitenberg, M. J., Holtmaat, A. J., De Wit, J., De Winter, F., and Verhaagen, J. (1999). Expression of the gene encoding the chemorepellent semaphorin III is induced in the fibroblast component of neural scar tissue formed following injuries of adult but not neonatal CNS. Mol. Cell. Neurosci. $13,143-166$

Pasterkamp, R. J., and Kolodkin, A. L. (2003).Semaphorin junction: making tracks toward neural connectivity Curr. Opin. Neurobiol. 13, 79-89.

Pasterkamp, R. J., and Verhaagen, J. (2006). Semaphorins in axon regeneration: developmental guidance molecules gone wrong? Philos. Trans. R. Soc. Lond. B Biol. Sci. 361, 1499-1511.

Paxinos, G., and Watson, C. (1998). Th Rat Brain in Stereotaxic Coordinates. San Diego, CA: Academic Press.

Perala, N. M., Immonen, T., and Sariola, H. (2005). The expression of plexins during mouse embryogenesis. Gene Expr. Patterns 5, 355-362.

Piper, M., Plachez, C., Zalucki, O., Fothergill, T., Goudreau, G. Erzurumlu, R., Gu, C., and Richards, L. J. (2009). Neuropilin 1-Sema signaling regulates crossing of cingulate pioneering axons during development of the corpus callosum. Cereb. Cortex 19(Suppl. 1):i11-i21.

Potiron, V., and Roche, J. (2005). Class 3 semaphorin signaling: the end of a dogma. Sci. STKE, 2005, pe24.

Prensa, L., Cossette, M., and Parent, A. (2000). Dopaminergic innervation of human basal ganglia. J. Chem. Neuroanat. 20, 207-213.

Runker, A. E., Little, G. E., Suto, F. Fujisawa, H., and Mitchell, K. J. (2008) Semaphorin-6A controls guidance of corticospinal tract axons at multiple choice points. Neural Dev. 3, 34.

Schwarz, Q., Waimey, K. E., Golding, M., Takamatsu, H., Kumanogoh, A., Fujisawa, H., Cheng, H. J., and Ruhrberg, C. (2008). Plexin A3 and plexin A4 convey semaphorin signals during facial nerve development. Dev Biol. 324, 1-9.

Spinelli, E. D., McPhail, L. T., Oschipok, L. W., Teh, J., and Tetzlaff, W. (2007). Class A plexin expression in axotomized rubrospinal and facial motoneurons. Neuroscience 144, 1266-1277.

Suto, F., Ito, K., Uemura, M., Shimizu, M., Shinkawa, Y., Sanbo, M., Shinoda, T. Tsuboi, M., Takashima, S., Yagi, T., and Fujisawa, H. (2005). Plexin-a4 mediates axon-repulsive activities of both secreted and transmembrane semaphorins and plays roles in nerve fiber guidance. J. Neurosci. 25, 3628-3637.

Suto, F., Murakami, Y., Nakamura, F., Goshima, Y., and Fujisawa, H. (2003) Identification and characterization of a novel mouse plexin, plexin-A4 Mech. Dev. 120, 385-396.

Suto, F., Tsuboi, M., Kamiya, H., Mizuno H., Kiyama, Y., Komai, S., Shimizu, M., Sanbo, M., Yagi, T., Hiromi, Y. Chedotal,A., Mitchell, K. J., Manabe, T. and Fujisawa, H. (2007). Interactions between plexin-A2, plexin-A4, and semaphorin 6A control lamina-restricted projection of hippocampal mossy fibers. Neuron 53, 535-547.

Torre, E. R., Gutekunst, C. A., and Gross, R. E. (2010). Expression by midbrain dopamine neurons of Sema3A and $3 \mathrm{~F}$ receptors is associated with chemorepulsion in vitro but a mild in vivo phenotype. Mol. Cell. Neurosci. 44, 135-153.

Tsim, T. Y., Wong, E. Y., Leung, M. S., and Wong, C. C. (2004). Expression of axon guidance molecules and their related genes during development and sexual differentiation of the olfactory bulb in rats. Neuroscience 123 , 951-965.

Waimey, K. E., Huang, P. H., Chen, M., and Cheng, H. J. (2008). Plexin-A3 and plexin-A4 restrict the migration of sympathetic neurons but not their neural crest precursors. Dev. Biol. 315 , $448-458$.

Yamamoto, M., Suzuki, K., Okuno, T., Ogata, T., Takegahara, N., Takamatsu, H., Mizui, M., Taniguchi, M., Chedotal, A., Suto, F., Fujisawa, H. Kumanogoh, A., and Kikutani, H. (2008). Plexin-A4 negatively regulates $\mathrm{T}$ lymphocyte responses. Int. Immunol. 20, 413-420.

Yaron, A., Huang, P. H., Cheng, H. J., and Tessier-Lavigne, M. (2005). Differential requirement for Plexin-A3 and -A4 in mediating responses of sensory and sympathetic neurons to distinct class 3 Semaphorins. Neuron 45, 513-523.

Yu, T. W., and Bargmann, C. I. (2001). Dynamic regulation of axon guidance. Nat. Neurosci. 4(Suppl.), 1169-1176.

Conflict of Interest Statement: The authors declare that the research was conducted in the absence of any commercial or financial relationships that could be construed as a potential conflict of interest.

Received: 28 December 2009; paper pending published: 18 February 2010; accepted: 16 May 2010; published online: 13 July 2010

Citation: Gutekunst C-A, Stewart EN and Gross RE (2010) Immunohistochemical distribution of PlexinA4 in the adult rat central nervous system. Front. Neuroanat. 4:25. doi: 10.3389/fnana.2010.00025 Copyright $(0) 2010$ Gutekunst, Stewart and Gross. This is an open-access article subject to an exclusive license agreement between the authors and the Frontiers Research Foundation, which permits unrestricted use, distribution, and reproduction in any medium, provided the original authors and source are credited. 